\title{
EL TRASVASE JÚCAR-VINALOPÓ. UNA RESPUESTA A LA SOBREEXPLOTACIÓN DE ACUÍFEROS
}

\author{
M Inmaculada López Ortiz y Joaquín Melgarejo Moreno \\ Departamento Análisis Económico Aplicado \\ Universidad de Alicante
}

\section{RESUMEN}

El sistema Vinalopó-Alacantí en la provincia de Alicante es un espacio caracterizado por la escasez de recursos hídricos y por un gran desarrollo de las aguas subterráneas. Estas aguas han permitido el abastecimiento de buena parte de los municipios de la provincia y de una agricultura muy avanzada, caracterizada por su eficiencia y productividad.

Con el objeto de paliar los graves problemas de sobreexplotación de las aguas subterráneas y restituir el equilibrio hídrico, el Plan Hidrológico de la cuenca del Júcar de 1988 previó la realización de un trasvase desde el Júcar al Vinalopó, éste fue aprobado por unanimidad y fue declarado de interés general por el Estado y sus obras se incluyeron en el Plan Hidrológico Nacional de 2001. La obra del trasvase se inició en 2002, con toma en Cortes de Pallás. En 2005, cuando se había ejecutado más del 52\% del presupuesto el Ministerio de Medio Ambiente, de forma unilateral, decidió el cambio de toma y trazado, lo cual tendrá repercusiones sobre la disponibilidad de caudales, la calidad del agua trasvasada, los costes de construcción y explotación, la financiación tanto de la UE como de los particulares, y en los plazos de ejecución y puesta en servicio de la infraestructura. Esta decisión ha despertado una fuerte oposición en los potenciales usuarios, agrupados en la Junta Central de Usuarios del Vinalopó, Alacantí y Consorcio de Aguas de la Marina Baja (JCU).

Palabras clave: Trasvases, aguas subterráneas, política hidráulica, economía de los recursos naturales, agua y medioambiente.

\section{ABSTRACT}

The Vinalopó-Alicante System in the province of Alicante, Spain, is a space characterized for the shortage of hydric resources but a great development of underground waters. These underground waters have allowed the water supply in most of the municipalities of the province and, at the same time, the development of a very advanced agriculture, well known for its efficiency and productivity.

In order to alleviate the serious problems caused by an excessive exploitation of the underground water and to restore the former hydric balance, the Hydrologic Plan of the 
Jucar River in 1988, anticipated the necessity of creating an interbasin diversion from the Jucar River to the Vinalopó. This one was approved unanimously and it was declared of general interest by the State and their works were included in the Hydrologic Plan of 2001. The first works of the interbasin diversion began in 2002, with the taking placed in Cortes de Pallás. In 2005, when more than 52\% of the budget was already executed, the Ministry of Environment, in a one-sided decision, changed the taking and the layout. This will have direct repercussions on the availability of the volume, the quality of the transferred water and construction and exploitation costs. Funds availability from the EU and from private sources as well as deadlines of the implementation of the infrastructure will be also affected.

This decision has provoked a strong opposition in the potential consumers, gathered in the Central Meeting of Users of the Vinalopó, Alacantí and Consorcio de Aguas de la Marina Baja (JCU).

Key words: Interbasin diversion, underground waters, hydric policy, economy of the natural resources, water and environment.

\section{Introducción}

El sistema Vinalopó-Alacantí (provincia de Alicante) es un espacio caracterizado por la escasez de recursos hídricos y por un gran desarrollo de las aguas subterráneas, sobre todo, a partir de la segunda mitad del siglo XX. Estas aguas han permitido el abastecimiento de buena parte de los municipios de la provincia y de una agricultura muy avanzada, caracterizada por su eficiencia y productividad.

Históricamente, al menos desde 1420, se viene pensando en trasvasar aguas desde el río Júcar, en la provincia de Valencia, al río Vinalopó, en Alicante; diferentes estudios e informes así lo atestiguan, por lo que podemos afirmar que se trata de uno de los proyectos de trasvase entre dos ríos más antiguos en España.

Con el objeto de paliar los graves problemas de sobreexplotación de las aguas subterráneas, el Plan Hidrológico de la cuenca del Júcar de 1988 previó la realización de un trasvase desde el Júcar al Vinalopó, ambos dentro de la misma Demarcación Hidrográfica. El trasvase fue aprobado por unanimidad, con el voto favorable de todos los afectados. Posteriormente, fue declarado de interés general por el Estado y sus obras se incluyeron en el Plan Hidrológico Nacional de 2001. De este modo, se le daba el mayor rango legal posible a un proyecto que tenía, entre otros, una clara orientación ambiental, puesto que el objetivo perseguido era el de la restauración del equilibrio hídrico perdido como resultado de la sobreexplotación de acuíferos en el río Vinalopó.

La obra del trasvase se inició en 2002, para ello contó con la declaración de impacto ambiental favorable, dispuso del informe favorable del Banco Europeo de Inversiones y de financiación europea a través de los Fondos FEDER, junto con las aportaciones del Ministerio de Medio Ambiente y, lo que fue más original, con el compromiso financiero de los usuarios. El trasvase se encomendó a la sociedad estatal Aguas del Júcar S.A., con la que la Junta Central de Usuarios del Vinalopó, Alacantí y Consorcio de Aguas de la Marina Baja (JCU) suscribió un convenio de financiación y explotación de la obra.

Las Elecciones Generales de marzo de 2004 significaron un cambio de Gobierno y un viraje extraordinario de la política hidráulica seguida hasta el momento por el Ministerio de Medio Ambiente. Uno de los efectos de este viraje será la modificación sustancial del proyecto de actuación del trasvase Júcar-Vinalopó, pese a que se había ejecutado ya más de $52 \%$ del presupuesto de las obras. En julio de 2005, el Ministerio de Medio Ambiente, 
de forma unilateral, modificó radicalmente el proyecto en ejecución, cambiando el punto de toma y el trazado del trasvase, lo cual tenía repercusiones sobre la disponibilidad de caudales, la calidad del agua trasvasada, los costes de construcción y explotación, la financiación tanto de la UE como de los particulares, y en los plazos de ejecución y puesta en servicio de la infraestructura.

\section{Alicante: una provincia con recursos hídricos limitados sometidos a un intenso aprovechamiento}

En la provincia de Alicante la disponibilidad de recursos de agua, la gestión de la demanda y la planificación hidrológica tienen como referencia básica la división administrativa que establecen las confederaciones hidrográficas del Júcar y del Segura. Condicionantes climáticas e hidrográficas explican la penuria natural de recursos hídricos existente en esta provincia. Una penuria que se ha visto intensificada por el crecimiento de la demanda producido durante la segunda mitad del siglo XX. Los usos están dominados por el consumo agrícola y por el progresivo crecimiento de los abastecimientos urbano-turístico.

En efecto, la oferta de recursos disponible, además de escasa y limitada, está sujeta a intenso aprovechamiento, lo que ha desencadenado graves problemas de sobreexplotación, degradación y contaminación tanto de las aguas superficiales como de las subterráneas. A los recursos aportados por el río Segura y por la explotación de acuíferos, se han unido durante las últimas décadas los proporcionados por la Mancomunidad de los Canales del Taibilla, el trasvase Tajo-Segura y los derivados de la creciente utilización de fuentes no convencionales, en las que se incluye la reutilización de residuales y la producción de aguas desaladas (Prat y Melgarejo, 2006). En la actualidad, este panorama se vería reforzado por el trasvase Júcar-Vinalopó, que se encuentra en la fase final de su ejecución.

La escasez de recursos hídricos es, sin lugar a dudas, el rasgo determinante de buena parte de la provincia, dicho fenómeno está motivado por causas climáticas y por condicionantes hidrográficos e hidrogeológicos. Cabe destacar, en este sentido, que, en su mayor parte, la provincia de Alicante se adscribe a la seca región climática del Sureste peninsular o pertenece a su entorno inmediato, con precipitaciones exiguas e irregulares, disminuida además su eficacia por la fuerte concentración horaria y una cuantiosa evapotranspiración potencial. En efecto, en gran parte de la provincia, la evapotranspiración potencial suele superar ampliamente la precipitación registrada, sobre todo en las comarcas meridionales; mientras que la eficacia de las lluvias puede verse reducida durante los episodios torrenciales por la intensidad con que se registran y por la cercanía al mar de los colectores fluviales autóctonos.

En cuanto a las características hidrológicas, a excepción del Segura, el resto de casos, se trata de ríos-ramblas, definidos por su corto caudal, módulos relativos ínfimos, elevada irregularidad interanual, durísimos estiajes veraniegos y con máximos en primavera y otoño, estación ésta que registra las mayores crecidas, capaces de multiplicar, excepcionalmente, por mil o más el débito absoluto.

En cuanto a las aguas subterráneas, éstas vienen definidas por una clara variación de las características de los acuíferos en función de su geología de norte a sur de la provincia. Al norte, por ser la estructura de los materiales menos accidentada y existir mayor presencia de rocas permeables, se encuentran los acuíferos con mejores características en cuanto a extensión, capacidad de almacenamiento, etc. Se trata de acuíferos que aportan caudales altos en bombeos, con gran capacidad de recuperación y grandes reservas. Hacia el sur, el aumento de formaciones margosas y arcillosas junto a la existencia de una mayor complejidad estructural ocasionan la presencia de acuíferos más reducidos y con peores 
características hidrogeológicas. En la zona de la Vega Baja, Bajo Vinalopó y Alicante, las formaciones acuíferas están constituidas por materiales arenosos y calizos de poco espesor, de escasos recursos y baja calidad.

Precisamente, la escasez de recursos superficiales ha favorecido que la principal vía convencional para atender la intensificación de la demanda producida en Alicante haya consistido en la explotación de sistemas acuíferos. Estos aportan unos $365 \mathrm{hm}^{3} /$ año, de los cuales $165 \mathrm{hm}^{3} /$ año corresponden a reservas no renovables, especialmente en el eje del Vinalopó. En años de sequía, la sobreexplotación supera los 250 hm³/año. Con estos recursos se atienden usos con gran valor añadido como los hortofrutícolas y los urbano-turísticos (más de 75.000 ha se riegan con aguas subterráneas). La situación de sobreexplotación más grave la encontramos en la cuenca del Vinalopó, en sistemas como Quibas y Sierra del Cid, donde el número de sondeos abandonados supera el $80 \%$, y en otros, como la Sierra de Crevillente, donde las profundidades de extracción superan los 500 metros.

En el análisis de la situación actual del medio ambiente del Programa Operativo Integrado de la Comunidad Valenciana (2000-2006), se cuantifica en 412 hm³/año el déficit hídrico total en el territorio de la Comunidad Valenciana. En él se indica que el déficit es especialmente crítico en la zona del Vinalopó-Alacantí, con una carencia de $220 \mathrm{hm}^{3} /$ año, y de $21 \mathrm{hm}^{3} /$ año en la comarca de la Marina Baja. También se argumenta que los desajustes entre recursos y demandas en estas zonas «sigue siendo el problema más apremiante, máxime si se tiene en cuenta que son además zonas de gran actividad socioeconómica, fuerte componente estacional y relevante implantación industrial».

\section{Situación de los pozos en la Cuenca del Vinalopó}

En el sistema de explotación Vinalopó-Alacantí, en 2002, las demandas de agua, ordenadas de mayor a menor fueron: la agrícola $(47,8 \%)$, urbana $(45,1 \%)$ e industrial $(7,1 \%)$ respecto de la demanda total, que se estimaba en unos $295 \mathrm{hm}^{3}$ anuales. En el sistema de la Marina Baja la principal demanda es la urbana, con un 59,40\% respecto a la total (67 $\mathrm{hm}^{3}$ anuales en el año 2002), seguida de la agrícola con un 40,28\%. La demanda industrial es prácticamente inapreciable, ya que sólo representa el $0,32 \%$ respecto a la demanda total (CHJ, 2004).

El sistema de explotación Vinalopó-Alacantí se encuentra situado en la zona más meridional del ámbito de la Confederación Hidrográfica del Júcar (CHJ), tal y como se muestra en la Figura 1.

Se localiza en la zona sur de la provincia de Alicante e incluye una pequeña parte de la zona meridional de la provincia de Albacete. Comprende las cuencas propias de los ríos Monnegre, Rambla de Rambuchar, Vinalopó y las subcuencas litorales comprendidas entre el límite norte del término municipal de El Campello y la divisoria con la Confederación Hidrográfica del Segura. De este sistema de explotación se considera excluido todo aprovechamiento agrícola que reciba de manera exclusiva aguas procedentes de la Confederación Hidrográfica del Segura.

Las zonas regadas en el sistema Vinalopó-Alacantí conforman las denominadas Unidades de Demanda Agraria (UDAs), que son agrupaciones de comunidades de regantes y de usuarios particulares con características homogéneas en los sistemas de riego empleados (CHJ, 2004). En el sistema Vinalopó-Alacantí hay definidas 11 UDAs, las cuales se muestran en la Tabla 1, junto con el porcentaje de agua procedente de aguas subterráneas y la eficiencia global que tiene la UDA en el riego (conducción principal, distribución y aplicación). 


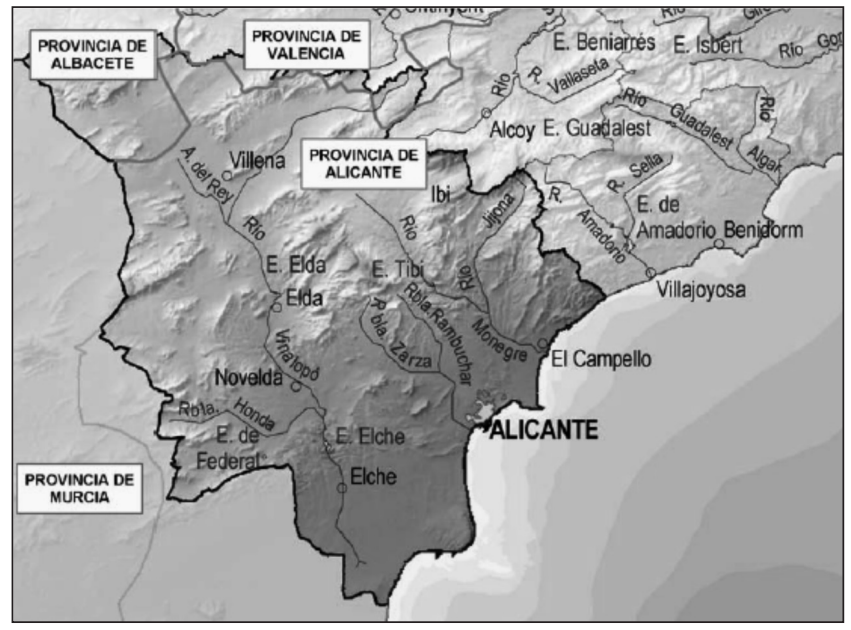

Figura 1. Sistema Vinalopó-Alacantí

Tabla 1

UNIDADES DE DEMANDA AGRARIA (UDA) INCLUIDAS EN PARTE EN EL SISTEMA VINALOPÓ-ALACANTÍ

\begin{tabular}{|c|c|c|c|c|}
\hline UDA & Nombre UDA & Origen & \begin{tabular}{|c|}
$\%$ Origen \\
Subterráneo
\end{tabular} & $\begin{array}{c}\text { Efic } \\
\text { Global }\end{array}$ \\
\hline $081040 \mathrm{~A}$ & Riegos de Almansa ${ }^{(1)}$ & Mixto & $80 \%$ & $50 \%$ \\
\hline $081063 \mathrm{~A}$ & Pequeños regadíos. Alcoia y El Comtat (2) & Superficial & $0 \%$ & $75 \%$ \\
\hline $081072 \mathrm{~A}$ & Riegos del Monnegre & Superficial & $0 \%$ & $90 \%$ \\
\hline $081072 B$ & Riegos del río Jijona & Superficial & $0 \%$ & $90 \%$ \\
\hline $081073 \mathrm{~A}$ & Riegos de la cabecera del río Monnegre & Mixto & $80 \%$ & $90 \%$ \\
\hline $081074 \mathrm{~A}$ & Riegos subterráneos del Alto Vinalopó & Subterráneo & $100 \%$ & $90 \%$ \\
\hline $081074 \mathrm{~B}$ & Riegos mixtos del Alto Vinalopó & Mixto & $80 \%$ & $90 \%$ \\
\hline $081076 \mathrm{~A}$ & Riegos del Medio Vinalopó & Subterráneo & $100 \%$ & $90 \%$ \\
\hline $081077 \mathrm{~A}$ & Bajo Vinalopó & Subterráneo & $100 \%$ & $90 \%$ \\
\hline $081078 \mathrm{~A}$ & Alacantí & Mixto & $80 \%$ & $90 \%$ \\
\hline $081079 \mathrm{~A}$ & $\begin{array}{c}\text { Riegos de Levante MI (agua procedente } \\
\text { de la Confederación Hidrográfica del } \\
\text { Segura) }\end{array}$ & Superficial & $0 \%$ & $90 \%$ \\
\hline
\end{tabular}

(1) Prácticamente la totalidad de la UDA se encuentra fuera del sistema Vinalopó- Alacantí.

(2) Situada la mayor parte de la UDA fuera del sistema Vinalopó- Alacantí. 
A continuación se analiza el estado actual de los pozos del Vinalopó a través de la información facilitada por la Junta Central de Usuarios del Vinalopó, L'Alacantí-y Consorcio de Aguas de la Marina Baja (JCU).

Tabla 2

VOLUMEN DE AGUA EXTRAÍDO EN LOS POZOS DEL VINALOPÓ

\begin{tabular}{|c|c|c|c|}
\hline CODUHG & UHG & VOLUMEN $\left(\mathrm{m}^{3}\right)$ & TOTAL $\left(\mathrm{m}^{3}\right)$ \\
\hline 08.32 & Sierra Grossa & 5.406 & \multirow{15}{*}{$\begin{array}{l}\overrightarrow{8} \\
8 \\
\dot{8} \\
8 \\
\dot{8} \\
\dot{0} \\
+\end{array}$} \\
\hline 08.33 & Almansa & 1.460 .381 & \\
\hline 08.34 & Sierra Oliva & 1.622 .901 & \\
\hline 08.35 & Jumilla - Villena & 24.006 .696 & \\
\hline 08.36 & Villena - Benejama & 31.208 .089 & \\
\hline 08.40 & Sierra Mariola & 3.967 .744 & \\
\hline 08.41 & Peñarrubia & 3.570 .922 & \\
\hline 08.42 & Carche - Salinas & 11.925 .267 & \\
\hline 08.43 & Argueña - Maigmo & 1.942 .463 & \\
\hline 08.44 & Barracones - Carrasqueta & 1.159 .050 & \\
\hline 08.49 & Agost - Monegre & 191.505 & \\
\hline 08.50 & Sierra del Cid & 2.851 .050 & \\
\hline 08.51 & Quibas & 3.886 .652 & \\
\hline 08.52 & Crevillente & 10.611 .178 & \\
\hline 08.99 & Interés local & 2.059 .790 & \\
\hline
\end{tabular}

Fuente: JCU, 2006. UHG: Unidades hidrogeológicas.

Los $17,12 \mathrm{hm}^{3} /$ año destinados al abastecimiento del Alacantí (AMAEM, ayuntamientos de Agost y de Jijona, y J.M. Los Frutales (Elche) y Sociedad. Canal de la Huerta de Alicante), ponen de manifiesto que la desalación prevista en el programa AGUA no corrige la sobreexplotación de los acuíferos del Alto Vinalopó, porque como máximo se dejarían de enviar estos $17,12 \mathrm{hm}^{3} /$ año (Tabla 3 ).

Los $100,4 \mathrm{hm}^{3}$ totales hacen referencia al aproximadamente $70 \%$ de las extracciones reales del conjunto del sistema Vinalopó, por lo que tan sólo quedarían sin mediciones concretas alrededor de unos 30-40 hm³/año (los pequeños pozos de menos de $7.000 \mathrm{~m}^{3} /$ año, y otros no controlados) (Tabla 3).

Los volúmenes de demanda requeridos con aguas subterráneas en las diferentes unidades hidrogeológicas se muestran en la tabla 4. Estas cifras se han estimado a partir de los valores de población permanente y estacional, de las superficies regadas y de las dotaciones establecidas en los trabajos de actualización y seguimiento del Plan Hidrológico de Cuenca (CHJ, 2004). 
Tabla 3

DISTRIBUCIÓN DE LOS VOLÚMENES EXTRAIIDOS SEGÚN EL DESTINO

\begin{tabular}{|c|c|c|c|}
\hline \multicolumn{4}{|c|}{ DISTRIBUCIÓN DE CAUDALES SEGÚN DESTINO } \\
\hline Titular & Zona destino & Volumen $\left(\mathrm{m}^{3}\right)$ & Totales $\left(\mathbf{m}^{3}\right)$ \\
\hline \multirow{7}{*}{ 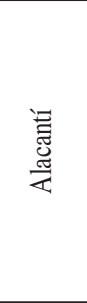 } & AMAEM & 7.524 .613 & \multirow{7}{*}{ 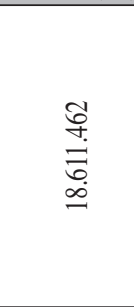 } \\
\hline & AYTO. AGOST & 457.118 & \\
\hline & AYTO. JIJONA & 811.671 & \\
\hline & C.R. VIRGEN DE LA PAZ-EL CANALILLO DE AGOST & 1.409 .097 & \\
\hline & C.R.S.R. HUERTA DE ALICANTE & 81.766 & \\
\hline & J.M. LOS FRUTALES & 1.489 .818 & \\
\hline & SDAD. CANAL DE LA HUERTA DE ALICANTE & 6.837 .379 & \\
\hline \multirow{32}{*}{  } & AGRÍCOLA LA MISIÓN & 1.144 .811 & \multirow{32}{*}{ 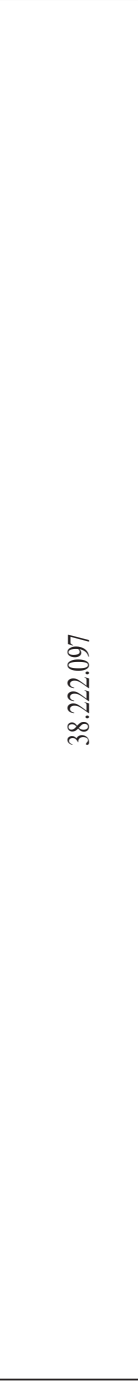 } \\
\hline & AGRÍCOLAS NEW ROCK & 491 & \\
\hline & AGRÍCOLAS VERA & 331.237 & \\
\hline & AYTO. BENEJAMA & 292.745 & \\
\hline & AYTO. BIAR & 504.734 & \\
\hline & AYTO. CAMPO DE MIRRA & 115.159 & \\
\hline & AYTO. CASTALLA & 275.666 & \\
\hline & AYTO. CAUDETE & 1.099 .554 & \\
\hline & AYTO. DE CAÑADA & 257.221 & \\
\hline & AYTO. ELDA & 3.571 .886 & \\
\hline & AYTO. ONIL & 126.368 & \\
\hline & AYTO. SAX & 141.745 & \\
\hline & AYTO. VILLENA & 2.995 .825 & \\
\hline & BENJAMÍN LAFUENTE & 448.136 & \\
\hline & BODEGAS E. MENDOZA & 10.910 & \\
\hline & C.G.U.A.V. (BATERÍA 1) & 499.575 & \\
\hline & C.G.U.A.V. (BATERÍA 2) & 3.481 .785 & \\
\hline & C.G.U.A.V. (BATERÍA 3) & 2.516 .150 & \\
\hline & C.G.U.A.V. (BATERÍA 4) & 2.157 .405 & \\
\hline & C.G.U.A.V. (BATERÍA 5) & 1.495 .131 & \\
\hline & C.G.U.A.V. (BATERÍA 6) & 1.875 .599 & \\
\hline & C.G.U.A.V. (BATERÍA 7) & 712.492 & \\
\hline & C.R. HEREDAMIENTOS AGUAS DE BOGARRA & 488.016 & \\
\hline & C.R. HUERTA Y PARTIDAS DE VILLENA & 4.121 .285 & \\
\hline & C.R. SAN CRISTÓBAL - BIAR & 902.055 & \\
\hline & C.R. VILLENA & 2.319 .135 & \\
\hline & CASA PEÑAS & 413.260 & \\
\hline & DE LA TORRE C.B. & 54.652 & \\
\hline & EXPLOTACIONES HORTOFRUTÍCOLAS & 705.400 & \\
\hline & FINCA DE EN MEDIO & 648 & \\
\hline & FINCA LAS CAÑAS & 32.049 & \\
\hline & HIJAS DE ANDRÉS NAVARRO C.B. & 0 & \\
\hline
\end{tabular}




\begin{tabular}{|c|c|c|c|}
\hline \multicolumn{4}{|c|}{ DISTRIBUCIÓN DE CAUDALES SEGÚN DESTINO } \\
\hline Titular & Zona destino & Volumen $\left(\mathrm{m}^{3}\right)$ & Totales $\left(\mathrm{m}^{3}\right)$ \\
\hline \multirow{14}{*}{  } & HIJAS DE ANDRÉS NAVARRO C.B. & 0 & \multirow{14}{*}{  } \\
\hline & INVERCÓN AGRÍCOLA & 120.534 & \\
\hline & J.M. LOS FRUTALES & 485.048 & \\
\hline & JOSE TORRES AMORÓS & 2.321 & \\
\hline & MICHAEL SPANGENBERG & 11.612 & \\
\hline & NAVARRETE GAMBÍN HNOS. & 451.983 & \\
\hline & PASCUAL RIBERA HURTADO & 0 & \\
\hline & PILAR JUAN PÉREZ & 40.552 & \\
\hline & S.A.T. 3562 SAX & 954.167 & \\
\hline & S.A.T. SANTA BÁRBARA & 222.662 & \\
\hline & S.A.T. SIERRA OLIVA & 1.429 .710 & \\
\hline & SDAD. CANAL DE LA HUERTA DE ALICANTE & 488.342 & \\
\hline & SDAD. COOP. AGUAS DEL PARAIISO & 634.543 & \\
\hline & SDAD. COOP. HONDO NOGUERAS & 289.498 & \\
\hline \multirow{19}{*}{ 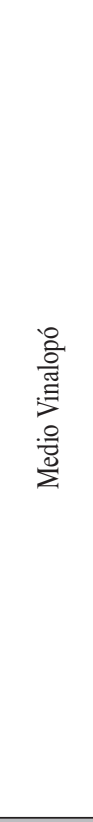 } & AMAEM & 7.524 .614 & \multirow{19}{*}{ 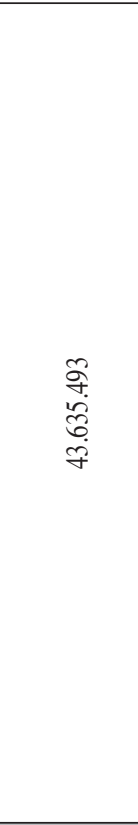 } \\
\hline & AYTO. MONÓVAR & 232.751 & \\
\hline & AYTO. PETRER & 26.292 & \\
\hline & C.G.U.A.V.(BATERÍA 1) & 3.793 .163 & \\
\hline & C.G.U.M.V. (BATERÍA 8) & 4.533 .755 & \\
\hline & C.R.HONDÓN-MONÓVAR & 935.889 & \\
\hline & C.R.LAROMANA & 3.448 .473 & \\
\hline & C.R. MONFORTE DEL CID & 400.270 & \\
\hline & C.R. NOVELDA & 5.947 .046 & \\
\hline & C.R. VIRGEN DE LA PAZ-EL CANALILLO DE AGOST & 24.194 & \\
\hline & C.U.AYTO. PINOSO - AYTO. ALGUEÑA & 225.445 & \\
\hline & GALERÍA SUIZOS & 5.786 .324 & \\
\hline & \begin{tabular}{|l|} 
S.A.T. BILAIRE \\
\end{tabular} & 182.121 & \\
\hline & S.A.T. RIEGOS HONDÓN & 3.175 .762 & \\
\hline & S.A.T. SAN ENRIQUE & 462.247 & \\
\hline & S.A.T. SANTA BÁRBARA ÚBEDA & 664.771 & \\
\hline & S.A.T. VIRGEN DE LAS NIEVES & 1.365 .227 & \\
\hline & \begin{tabular}{|l|} 
SDAD. CANAL DE LA HUERTA DE ALICANTE \\
\end{tabular} & 4.883 .842 & \\
\hline & S.A.T. VIRGEN DEL REMEDIO & 23.307 & \\
\hline Total & 100.469 .052 & & \\
\hline
\end{tabular}

Fuente: JCU, 2006.

Las demandas reales, no satisfechas en su totalidad, ascienden a más de $200 \mathrm{hm}^{3} / \mathrm{año}$, mientras que los derechos elevarían esta cifra hasta los $226 \mathrm{hm}^{3} / \mathrm{año}$. En la tabla 5 se pueden observar los balances de los acuíferos del Vinalopó-L'Alacantí en las diferentes unidades hidrogeológias. 
Tabla 4

VOLÚMENES DE AGUA SUBTERRÁNEA DEMANDADA EN EL ALTO Y MEDIO
VINALOPÓ

\begin{tabular}{|c|c|c|c|c|c|}
\hline Código UHG & Nombre UHG & $\begin{array}{c}\text { Demanda } \\
\text { urbana } \\
\left(\mathrm{hm}^{3} / \text { año) }\right.\end{array}$ & $\begin{array}{c}\text { Demanda } \\
\text { agrícola } \\
\left(\mathrm{hm}^{3} / \mathrm{año}\right)\end{array}$ & $\begin{array}{l}\text { Demanda } \\
\text { industrial } \\
\left(\mathrm{hm}^{3} / \mathrm{año}\right)\end{array}$ & $\begin{array}{c}\text { Demanda } \\
\text { total } \\
\left(\mathrm{hm}^{3} / \mathrm{año}\right)\end{array}$ \\
\hline $08.33 \mathrm{~V}$ & Almansa & 0,52 & 0,40 & 0 & 0,92 \\
\hline $08.34 \mathrm{~V}$ & Sierra Oliva & 0,88 & 1,49 & 0 & 2,37 \\
\hline 08.35 & Jumilla-Villena & 14,89 & 20,57 & 0,24 & 35,70 \\
\hline $08.36 \mathrm{~V}$ & Villena-Benejama & 25,74 & 22,06 & 6,43 & 54,24 \\
\hline 08.41 & Peñarrubia & 10,19 & 1,51 & 0,00 & 11,70 \\
\hline 08.42 & Carche-Salinas & 8,72 & 8,68 & 0,21 & 17,61 \\
\hline $\begin{array}{l}\text { Total Alto } \\
\text { Vinalopó }\end{array}$ & & 60,94 & 54,71 & 6,88 & 122,54 \\
\hline $08.40 \mathrm{~V}$ & Sierra Mariola & 7,51 & 2,52 & 1,35 & 11,38 \\
\hline 08.43 & Argueña-Maigmo & 5,74 & 4,08 & 0,16 & 9,98 \\
\hline $08.44 \mathrm{~V}$ & Barrancones- & & & & \\
\hline & Carrasqueta & 3,97 & 1,11 & 1,11 & 6,19 \\
\hline 08.49 & Agost-Monegre & 0,36 & 3,95 & 0,03 & 4,34 \\
\hline 08.50 & Sierra del Cid & 3,20 & 1,80 & 2,02 & 7,02 \\
\hline 08.51 & Quibas & 2,12 & 6,37 & 4,73 & 13,22 \\
\hline 08.52 & Crevillente & 1,66 & 12,49 & 3,11 & 17,26 \\
\hline 08.99 & Impermeable & 1,08 & 5,49 & 1,70 & 8,27 \\
\hline $\begin{array}{l}\text { Total Medio } \\
\text { Vinalopó }\end{array}$ & & 25,64 & 37,81 & 14,21 & 77,66 \\
\hline TOTAL & & 86,58 & 92,52 & 21,09 & 200,2 \\
\hline
\end{tabular}

Tabla 5

BALANCES DE LOS ACUÍFEROS DEL VINALOPÓ

\begin{tabular}{|c|c|c|c|c|c|c|}
\hline \multicolumn{7}{|c|}{ BALANCES DE LOS ACUÍFEROS DEL VINALOPÓ - L' ALACANTÍ (hm3/ año) } \\
\hline CODIGO & Nombre UHG & Derechos & $\begin{array}{c}\text { Recursos } \\
\text { Disponibles }\end{array}$ & $\begin{array}{l}\text { Déficit sobre } \\
\text { Derechos }\end{array}$ & $\begin{array}{l}\text { Júcar - } \\
\text { Vinalopó } \\
\text { (1) }\end{array}$ & $\begin{array}{l}\text { Sin resolver } \\
\text { DERECHOS }\end{array}$ \\
\hline UHG & & $\mathrm{hm}^{3}$ & $\mathrm{hm}^{3}$ & $\mathrm{hm}^{3}$ & $\mathrm{hm}^{3}$ & $\mathrm{hm}^{3}$ \\
\hline $08.33 \mathrm{~V}$ & Almansa & 0,07 & 0,65 & 0,00 & 0,00 & 0,00 \\
\hline $08.34 \mathrm{~V}$ & Sierra Oliva & 7,44 & 1,41 & $-6,03$ & 3,00 & $-3,03$ \\
\hline 08.35 & Jumilla-Villena & 37,24 & 1,31 & $-35,93$ & 20,80 & $-15,13$ \\
\hline $08.36 \mathrm{~V}$ & Villena-Benejama & 69,07 & 18,11 & $-50,96$ & 20,40 & $-30,56$ \\
\hline 08.40 & Sierra Mariola & 5,83 & 11,03 & 0,00 & 0,00 & 0,00 \\
\hline 08.41 & Peñarrubia & 9,48 & 0,94 & $-8,54$ & 2,15 & $-6,39$ \\
\hline 08.42 & Carche-Salinas & 15,97 & 1,89 & $-14,08$ & 8,15 & $-5,93$ \\
\hline 08.43 & Argueña-Maigmo & 13,70 & 2,44 & $-11,26$ & 0,65 & $-10,61$ \\
\hline $08.44 \mathrm{~V}$ & Barracones-Carras & 6,85 & 11,92 & 0,00 & 0,65 & 0,00 \\
\hline 08.49 & Agost-Monegre & 6,64 & 2,21 & $-4,43$ & 2,60 & $-1,83$ \\
\hline 08.50 & Sierra del Cid & 8,13 & 1,92 & $-6,21$ & 1,50 & $-4,71$ \\
\hline 08.51 & Quibas & 9,40 & 1,77 & $-7,63$ & 1,50 & $-6,13$ \\
\hline 08.52 & Crevillente & 22,95 & 1,14 & $-21,81$ & 5,60 & $-16,21$ \\
\hline 08.99 & Impermeable & 13,55 & 1,71 & $-11,84$ & 1,50 & $-10,34$ \\
\hline & DTAL & 226,32 & 58,45 & $-178,72$ & 68,50 & $-110,87$ \\
\hline
\end{tabular}

Fuente: CHJ (2004); JCU (2005).

(1): El trasvase son $80 \mathrm{hm}^{3}$, y de ellos $68,5 \mathrm{hm}^{3}$ se destinarían a sustitución. 
Con esta situación de creciente penuria hídrica la JCU, indica, además, que con la construcción de la desaladora Mutxamel/Campello (20 hm³/año), en obras, y la reutilización de unos $20 \mathrm{hm}^{3} /$ año, el déficit sería de $70,87 \mathrm{hm}^{3} /$ año (figura 2 ).

La situación de los acuíferos indicados anteriormente y la sobreexplotación de cada uno de ellos se representa gráficamente a continuación. En el figura 2 se puede observar, además de los acuíferos sobreexplotados, aquellos acuíferos excedentarios y los que se encuentran en equilibrio.

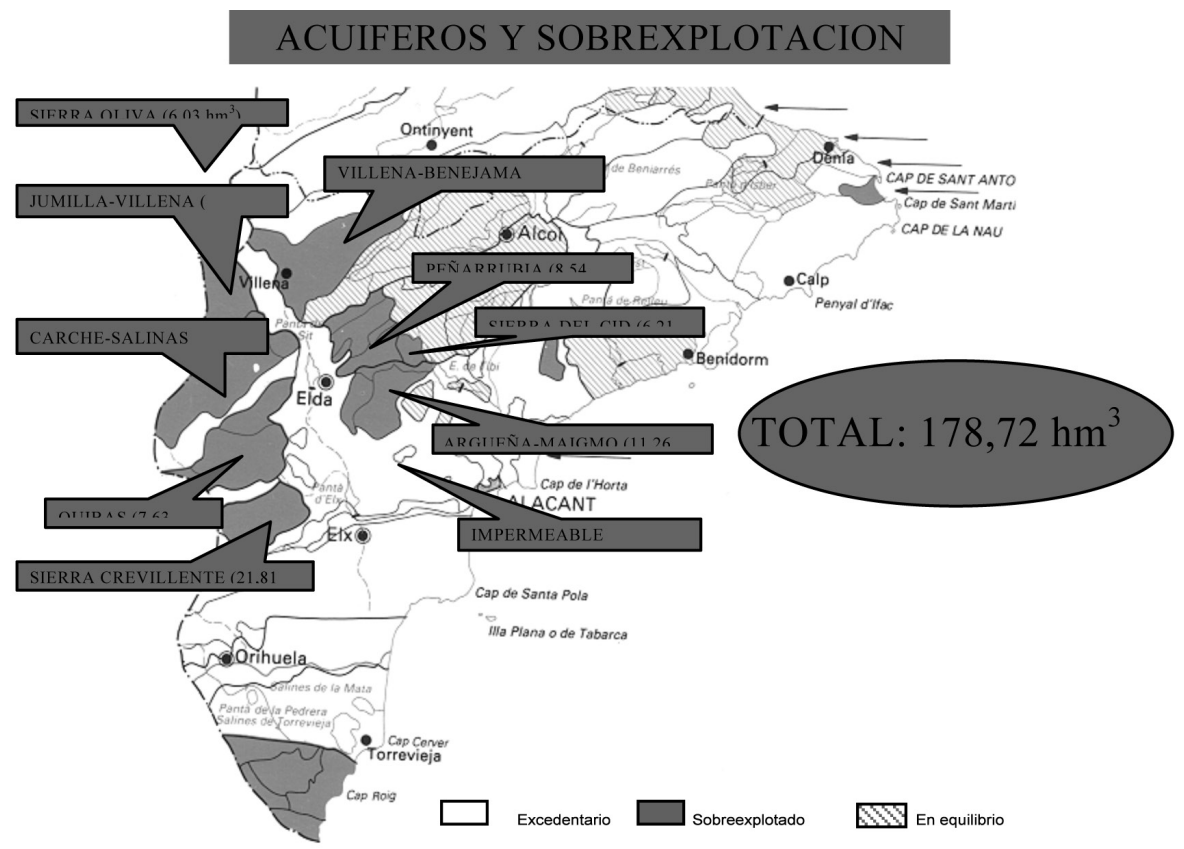

FIgURA 2. Déficit de los acuíferos del Vinalopó respecto a los derechos Fuente: JCU, 2005.

Las profundidades de extracción experimentan una caída constante, desde los años ochenta. Ejemplo de ello son los acuíferos de Sierra Oliva, Jumilla-Villena, Villena-Benejama, Peñarruibia, Sierra del Cid, Impermeable, Sierra de Crevillente (que se aproxima a los 600 metros de profundidad), Carche-Salinas, Quibas, Argueña- Maigmó (figura 3, 4 y 5). Todos ellos pertenecientes al ámbito geográfico del Valle del Vinalopó y L’Alacantí, donde el volumen de reservas no renovables utilizadas en el año 2005 ascendió a $110 \mathrm{hm}^{3} / \mathrm{año}^{1}$.

La Confederación de Júcar realizó en 2004 un balance hídrico del sistema VinalopóAlacantí (CHJ, 2004), en él que se estimó un déficit próximo a 95 hm³/año, que se distribuía entre las unidades hidrogeológicas de la forma que se muestra en la tabla 6.

1 La CHJ (2004) indicaba que existe un déficit total en las UHG del Vinalopó de 147,48 hm³/año, lo que coincide con la estimación realizada por la JCU (2005) cuando consideró el déficit en las UHG sobre la demanda. 


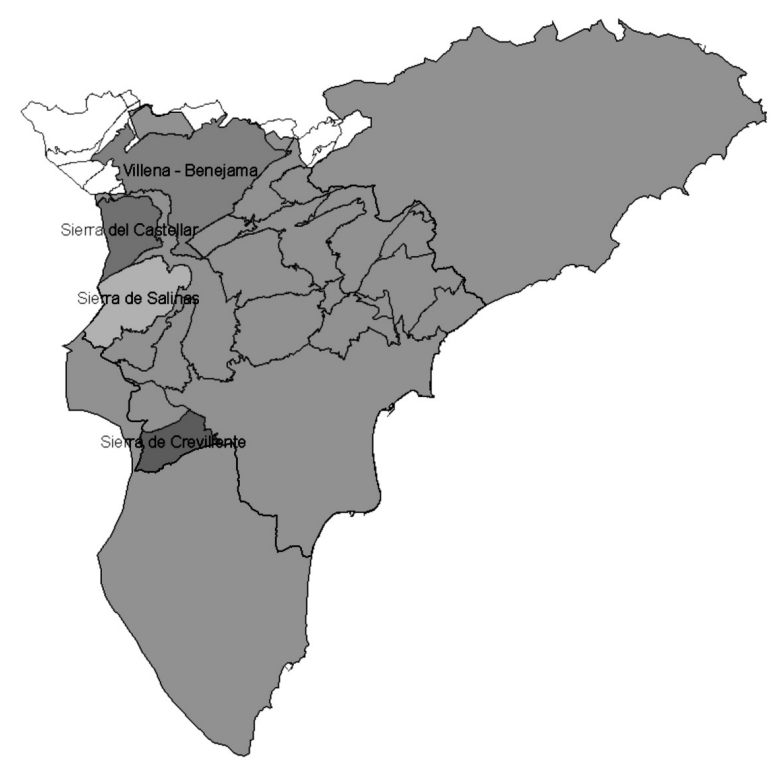

Figura 3. Localización de los acuíferos con graves descensos.

Fuente: Junta Central de Usuarios del Vinalopó. 2006.

Descensos Sierra Crevillente

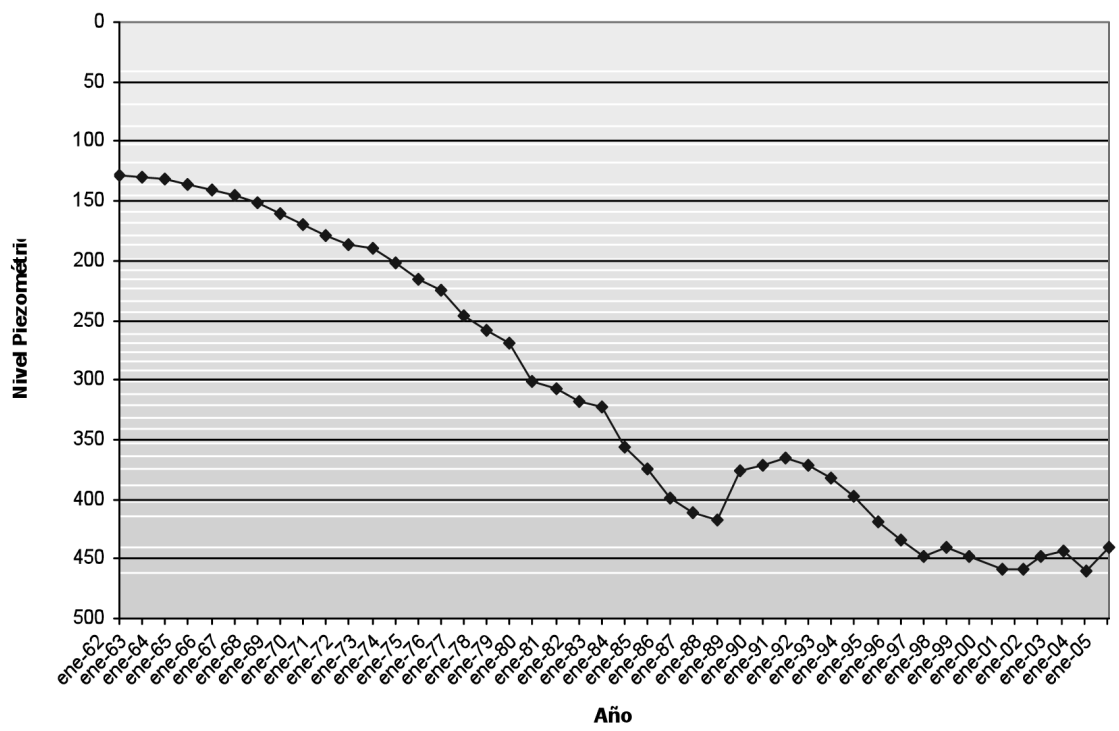

FIgURA 4. Descensos Sierra de Crevillente (1962-2005).

Fuente: Junta Central de Usuarios del Vinalopó. 2009. 
CARCHE - SALINAS

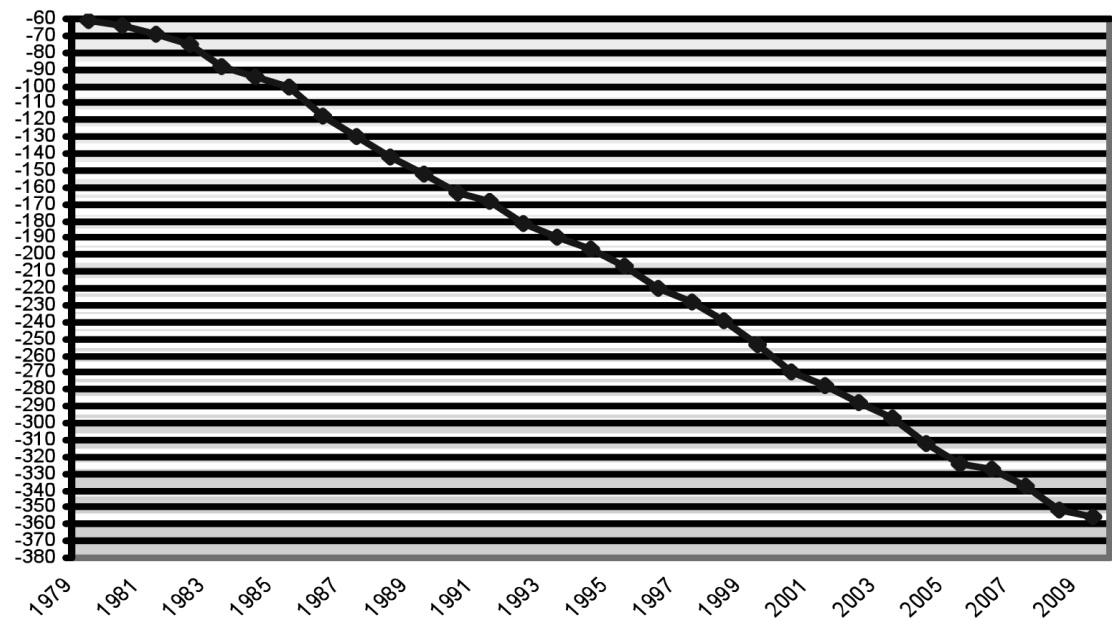

Figura 5. Descensos Carche-Salinas (1979-2009).

Fuente: Junta Central de Usuarios del Vinalopó. 2009.

Tabla 6

BALANCE HÍDRICO DE LAS UNIDADES HIDROGEOLÓGICAS DEL SISTEMA VINALOPÓ-ALACANTÍ (DATOS EN HM'/AÑO) ESTABLECIDO CON LOS USOS DE AGUA DEL AÑO 2004

\begin{tabular}{|c|c|c|c|c|c|}
\hline UHG & Nombre UHG & $\begin{array}{l}\text { Recurso disponible } \\
\left(\mathrm{hm}^{3} / \text { año) }\right.\end{array}$ & $\begin{array}{c}\text { Consumo } \\
\text { total } \\
\left(\mathrm{hm}^{3} / \text { año) }\right.\end{array}$ & $\mathrm{K}$ & $\begin{array}{c}\text { Déficit } \\
\left(\mathrm{hm}^{3} / \mathrm{año}\right)\end{array}$ \\
\hline AV $08.33 \mathrm{~V}$ & Almansa & 0,65 & 0,03 & 0,05 & 0 \\
\hline AV $08.34 \mathrm{~V}$ & Sierra Oliva & 1,41 & 5,51 & 3,91 & $-4,10$ \\
\hline AV 08.35 & Jumilla-Villena & 1,31 & 29,86 & 22,79 & $-28,55$ \\
\hline AV $08.36 \mathrm{~V}$ & Villena-Benejama & 18,11 & 46,08 & 2,54 & $-27,97$ \\
\hline AV 08.41 & Peñarrubia & 0,94 & 3,93 & 4,18 & $-2,99$ \\
\hline AV 08.42 & Carche-Salinas & 1,89 & 12,96 & 6,86 & $-11,07$ \\
\hline Total & Alto Vinalopó & 24,31 & 98,37 & & $-74,68$ \\
\hline MV $08.40 \mathrm{~V}$ & Sierra Mariola & 11,03 & 6,07 & 0,55 & 0 \\
\hline MV 08.43 & Argueña-Maigmo & 2,44 & 3,33 & 1,36 & $-0,89$ \\
\hline MV $08.44 \mathrm{~V}$ & Barrancones-Carrasqueta & 11,92 & 12,79 & 1,07 & $-0,87$ \\
\hline MV 08.49 & Agost-Monegre & 2,21 & 5,80 & 2,62 & $-3,59$ \\
\hline MV 08.50 & Sierra del Cid & 1,92 & 3,96 & 2,06 & $-2,04$ \\
\hline MV 08.51 & Quibas & 1,77 & 3,96 & 2,24 & $-2,19$ \\
\hline MV 08.52 & Crevillente & 1,14 & 8,78 & 7,70 & $-7,64$ \\
\hline 08,99 & Impermeable & 1,71 & 3,63 & 2,12 & $-1,92$ \\
\hline Total & Medio Vinalopó & 34,14 & 48,32 & & $-19,14$ \\
\hline TOTAL & & 58,45 & 146,69 & & $-93,82$ \\
\hline
\end{tabular}

Nivel de explotación: $\mathrm{K}_{\mathrm{UHG}}=$ bombeo total / recurso disponible. 
El volumen de sustitución propuesto de $68,5 \mathrm{hm}^{3}$, en una primera aproximación (detallado en la tabla 7), junto con el volumen de $11,5 \mathrm{hm}^{3}$ previsto para el abastecimiento en la Marina Baja, suma el volumen total de 80 hm³ $^{3}$ CHJ, 2004).

Tabla 7

SUSTITUCIÓN PROPUESTA EN PRIMERA APROXIMACIÓN

\begin{tabular}{ccc}
\hline UHG & Denominación & $\begin{array}{c}\text { Sustitución }\left(\mathrm{hm}^{3} / \text { año }\right. \\
\text { propuesta }\end{array}$ \\
\hline 08.34 & Sierra Oliva & 3,00 \\
08.35 & Jumilla-Villena & 20,80 \\
08.36 & Villena-Benejama & 20,40 \\
08.41 & Peñarrubia & 2,15 \\
08.42 & Carche-Salinas & 8,15 \\
08.43 & Argueña-Maigmo & 0,65 \\
08.44 & Barrancones-Carrasqueta & 0,65 \\
08.49 & Agost-Monegre & 2,60 \\
08.50 & Sierra del Cid & 1,50 \\
08.51 & Quibas & 1,50 \\
08.52 & Crevillente & 5,60 \\
08.99 & Impermeable & 1,50
\end{tabular}

TOTAL

68,50

\section{El Trasvase Júcar-Vinalopó}

El primer gran proyecto de trasvase de aguas que se plantea en España entre dos cuencas fluviales diferentes fue el Júcar-Vinalopó, según aparece recogido en un Acta del Concejo de Elche de 27 de mayo de 1420. En ella se da noticia de una carta de los Jurados de Villena acusando recibo de otra remitida a ellos, en la que se indica que «en lo que toca al sacar agua del río Xuquer». El Concejo Ilicitano consiguió el permiso de Villena y de Chinchilla, incluidas entonces dentro de la Corona de Castilla, para el paso de la conducción (Ramos Fernández, R. 1970).

La aspiración histórica de Alicante para acceder a las aguas del Júcar no se iba a abandonar durante los siglos siguientes como confirma una noticia sobre el Canal del Júcar (Gil Olcina, 1992), del año 1847, en la que se detalla que «en 1568, de orden del Duque de Maqueda, Marqués de Elche, se nivelaron los terrenos por donde podría venir una acequia de agua continua del río Júcar a Elche y en 1628 se trajo la relación y plano a Alicante con el intento de que el agua llegase a ella... pero quedó esto sin efecto a causa de la oposición que hizo la ciudad de Valencia». Este mismo documento recoge el proyecto del arquitecto Emilio Jover, con un coste de ejecución de 700.000 ducados, para la construcción de una conducción de 165 a $211 \mathrm{~km}$ de recorrido, con punto de toma entre la Roda y Villa de Vés, que serviría para derivar 700 hilos de los 2.100 que se aforaban en el estiaje de agosto. El canal regaría un gran número de municipios de la Mancha oriental, en provincia de Albacete, y entraría a Alicante por el Vinalopó, tras recorrer el valle de Ayora (Gil Olcina, 1992). El proyecto de Jover abre paso a otros en la segunda mitad del XIX, como los de D. Juan Bautista Peyronet (1857) y D. Rafael Santonja (1879), en los cuales se mantenían 
dos denominadores comunes (Bru Ronda, 1988). En primer lugar, que el punto de toma más oportuno estaría en el sector del Medio Júcar, entre La Roda y Villa de Vés, o en el sector de Cofrentes (Embarcaderos), para aprovechar la fosa tectónica de Ayora para enlazar con Villena, en el Alto Vinalopó. Los proyectos de trasvase del Júcar-Vinalopó planteados durante el siglo XX se multiplicarían a medida que aumentaban las necesidades de agua de los alicantinos, tanto para regadíos como para el desarrollo urbano-turístico.

Recién acabada la Guerra Civil, la Confederación Hidrográfica del Júcar auspició la redacción del Plan General de Riegos de la provincia de Alicante , que desarrollaba gran parte de las ideas del I Plan Nacional de Obras Hidráulicas de Manuel Lorenzo Pardo. La construcción de una serie de embalses en el Cabriel (Contreras), Júcar (Alarcón) y Turia (Generalísimo) garantizaría las demandas de la provincia de Valencia y, además, generaría recursos sobrantes que se sumarían a los del Tajo para atender un trasvase $(12 \mathrm{~m} 3 / \mathrm{s})$ desde Alarcón, con una conducción de $405 \mathrm{~km}$ que finalizaría en Villena, para el suministro de regadíos de la propia cuenca del Vinalopó, Campo de Alicante y Marina Baja. Años más tarde, en 1965, el «Anteproyecto General Técnico del Trasvase de Aguas del Río Júcar a las cuencas comprendidas entre los ríos Serpis y Vinalopó», elaborado por el Ministerio de Obras Públicas caería pronto en el olvido ante la redacción, en 1967, y posterior ejecución del «Anteproyecto General de Aprovechamiento conjunto de los recursos hidráulicos del Centro y Sureste de España. Complejo Tajo-Segura», que aportaría recursos del Alto Tajo a partir de 1979 a las comarcas del Bajo Vinalopó, Campo de Alicante y Bajo Segura (Bru Ronda, 1988).

En el Proyecto de Directrices del Plan Hidrológico del Júcar, hecho público en 1992, se incluía, entre las grandes obras a realizar con el horizonte del año 2002, el canal JúcarMarinas-Vinalopó, que se consideraba como «una transferencia interna de recursos, a corto plazo, de $100 \mathrm{hm}^{3}$ para atender los déficit de abastecimiento urbano y la sobreexplotación de acuíferos en las comarcas del Alacantí, Marina Baja y Vinalopó». El 6 de agosto de 1997 se realiza la aprobación del Plan Hidrológico de cuenca del Júcar mediante un consenso unánime e histórico alcanzado en el seno de su Consejo del Agua que incluía la realización de la transferencia Júcar-Vinalopó. El Consejo de Ministros del 17 de julio de 1998 autoriza la creación de la empresa pública Aguas del Júcar, S.A. que queda constituida el 21 de octubre del mismo año con la misión de llevar a cabo los estudios técnicos para comprobar la viabilidad del proyecto y realizar la ejecución de la obra.

Para cerrar el sentido de esta obra y poder realizar un perfecto uso y control de las aguas en la zona de destino, los usuarios se van agrupando en un primer instante en tres entidades: Comunidad General de Usuarios del Alto Vinalopó, Comunidad General de Usuarios del Medio Vinalopó-Alacantí y Consorcio de Aguas de la Marina Baja. Estas tres Entidades junto a Aguas del Júcar, S.A². firman en julio del 2001 el Convenio de regulación de la financiación de la ejecución y explotación de las obras de la Conducción Júcar-Vinalopó. En este documento ya se recoge la intención de los Usuarios de constituir una Junta Central que agrupe a todos los usuarios, siendo el 8 de enero del 2003 cuando se constituye la Junta Central de Usuarios del Vinalopó, L'Alacantí y Consorcio de Aguas de la Marina Baja por parte de la Confederación Hidrográfica del Júcar tras ser aprobados por unanimidad de todos los usuarios sus estatutos en la Asamblea General celebrada el 14 de octubre del 2002.

2 El 21 de octubre de 1998 se constituyó la Sociedad Estatal Aguas del Júcar, S.A., en virtud del Acuerdo del Consejo de Ministros de 17 de julio de 1998. Mediante el Convenio de Gestión Directa, autorizado en Consejo de Ministros de 18 de marzo de 1999 y firmado por el Ministerio de medio Ambiente y Aguas del Júcar, S.A. el 25 de marzo de 1999, se encomienda a esta Sociedad las actuaciones necesarias para la ejecución de la Conducción Júcar-Vinalopó. 
El trasvase Júcar-Vinalopó, incluido en el Plan Hidrológico Nacional (2001), es una actuación más con la que se intenta resolver el problema de escasez y déficit hídrico que afecta a la provincia de Alicante. El Pacto del Agua entre los gobiernos regionales de Castilla-La Mancha y la Comunidad Valenciana en 1997 quedó plasmado en el Artículo 32 del Plan Hidrológico de la cuenca del Júcar en el que se recoge la reserva de $80 \mathrm{hm}^{3} /$ año para paliar la sobreexplotación de acuíferos en el Vinalopó y garantizar los abastecimientos en el Campo de Alicante y en la Marina Baja. Estos caudales sólo podrán ser trasvasados tras garantizarse la satisfacción de los usos tradicionales del Júcar, La Albufera de Valencia y los nuevos regadíos previstos en La Mancha oriental.

\subsection{Objetivos del proyecto y beneficios en la zona receptora}

La construcción de la Conducción Júcar-Vinalopó tiene el objetivo de paliar la sobreexplotación de los acuíferos de la zona y corregir el déficit de los abastecimientos a poblaciones del área Vinalopó, Alacantí y Marina Baja. Para ello, el Plan Hidrológico de la cuenca del Júcar establece una reserva de $80 \mathrm{hm}^{3}$ de volumen máximo anual del sistema Júcar ${ }^{3}$.

Con esta actuación, se estima que resultarán beneficiados un millón de potenciales usuarios. La sustitución de caudales de los acuíferos del Vinalopó por los procedentes del Júcar permitirá, además de mejorar los abastecimientos a las poblaciones, la recuperación del nivel freático de los citados acuíferos. Por RDL 9/1988 de 28 de agosto, se declaró la conducción Júcar-Vinalopó como obra de interés general.

La urgencia de esta actuación viene motivada por la trascendencia social y económica de los suministros que soportan los acuíferos sobreexplotados del Vinalopó, de los cuales dependen unas 50.000 hectáreas de regadío de gran rentabilidad y el abastecimiento de agua potable de unos 800.000 habitantes residentes en Alicante y su área metropolitana, y en ciudades del Vinalopó como Elda, Petrer, Villena, Novelda o Aspe.

En la actualidad se aprovechan entorno a los $150 \mathrm{hm}^{3} /$ año procedentes de los acuíferos, de los cuales entre el 40 y el $60 \%$ son aguas procedentes de las reservas no renovables. No obstante, la situación de estas unidades hidrogeológicas puede clasificarse en dos grandes grupos, según A. Rico (2002):

A) Los acuíferos situados en el Medio Vinalopó, que agotaron sus reservas hace varias décadas, entre los que se incluyen la Sierra del Cid, Sierra de Crevillente y Quibas. En todos ellos, las profundidades de extracción superan los 400 metros, llegándose incluso a los 600, para lo que se precisa de electrobombas sumergibles de 1.000 $\mathrm{CV}$ de potencia, con costes próximos a 0,48 céntimos de $\square$ en energía eléctrica, con descensos superiores a 25 metros/año y una salinización superior a $2.000 \mathrm{mg} / \mathrm{l}$.

B) Los del Alto Vinalopó, que todavía almacenan importantes reservas, pero donde las profundidades de extracción ya superan en muchos sistemas los 300 metros y tienen una salinidad creciente. Dentro de este grupo, se incluyen las unidades de Carche-Salinas, Yecla-Villena-Benejama, Jumilla-Villena o Peñarrubia.

3 Con estos caudales se pretende aumentar la garantía de abastecimiento a las poblaciones en las comarcas receptoras, en cantidad y calidad suficiente. Aportar recursos hídricos a zonas actualmente regadas con agua procedente de acuíferos sobreexplotados, evitando el riesgo de abandono por falta de disponibilidad a corto plazo; en ningún caso se contempla el incremento de superficie o volumen para usos agrarios con los recursos transferidos por la conducción. Contribuir a la mejora ambiental de la zona receptora, mediante la sustitución de caudales subterráneos por superficiales que permitan la recuperación de los niveles piezométricos de los acuíferos sobreexplotados y una mayor calidad de los suelos, afectados localmente por procesos de salinización. 


\subsection{Las cautelas establecidas y los beneficios para la zona cedente}

El propio Plan Hidrológico de la cuenca del Júcar estableció una serie de cautelas para salvaguardar los intereses de la zona cedente, fijando un orden de prioridad, según el cual el volumen de transferencia sólo estaría garantizado tras haberse satisfecho las demandas de la Ribera del Júcar, del Canal Júcar-Turia, de los regadíos existentes y previstos en La Mancha oriental, de los abastecimientos de Albacete y de dar respuesta a diferentes requerimientos ambientales y a las concesiones hidroeléctricas. Así, la reserva de $80 \mathrm{hm}^{3} /$ año sólo se garantiza en el Plan del Júcar, si previamente se han satisfecho los usos tradicionales del Júcar (765 hm³/año), las necesidades de La Albufera de Valencia (100 hm³/año) y las de los nuevos regadíos situados en La Mancha Oriental.

En cuanto a los beneficios derivados para la zona cedente, merecen destacarse por su importancia las obras de modernización de la Acequia Real del Júcar, sin las cuales no sería posible realizar las transferencias, ya que posibilitan la existencia de los recursos a transferir del Júcar al Vinalopó. Estas obras de modernización están valoradas en 180.303.631 $\square$ (30.000 millones de pesetas), a financiar por la Consejería de Agricultura y por el Estado. Para ello, el 25 de junio de 2001, se firmó un convenio por el que los regantes valencianos ceden la titularidad del embalse de Alarcón a la Confederación Hidrográfica del Júcar. La firma de este acuerdo llevó anexo el compromiso de la Consejería de Agricultura de financiar el coste de la modernización de los sistemas de riego en la Acequia Real del Júcar, lo que generará un ahorro aproximado de $100 \mathrm{hm} 3 /$ año, cantidad que permite garantizar la conducción Júcar-Vinalopó. Hasta ese momento, el envío de los $80 \mathrm{hm}^{3} /$ año estaba condicionado a que hubiera recursos suficientes en los embalses de la Confederación. Las obras de modernización de la Acequia Real del Júcar, Escalona y Carcaixent, hasta ahora con sistema de riego tradicional, supondrán la transformación al sistema de riego por goteo de 20.000 hectáreas explotadas por 50.000 regantes. De este modo, se compensa el desembolso que realizaron los regantes en la construcción del embalse de Alarcón.

\subsection{Características de la obra del trasvase Júcar-Vinalopó desde Cortes de Pallás (2001)}

El trazado final de la conexión Júcar-Vinalopó tenía un recorrido total de 66,8 kilómetros, con inicio en el embalse de Cortes II y final en los Alhorines (Villena). La conducción estaba diseñada para soportar una capacidad de transporte de $7 \mathrm{~m}^{3} / \mathrm{s}$, lo que permitiría transferir a pleno rendimiento unos $200 \mathrm{hm}^{3} /$ año. Para la transferencia de $80 \mathrm{hm}^{3} / \mathrm{año}$, se previó que las instalaciones funcionarían durante 6 meses y medio, a un ritmo de 16 horas diarias. El destino final de la conexión era la central de turbinación de los Alhorines, aunque previamente el agua sería almacenada en el embalse de San Diego $\left(20 \mathrm{hm}^{3}\right)$, situado entre Villena y Fuente la Higuera.

El proyecto de «transferencia de recursos hídricos del Júcar al Vinalopó» obtuvo declaración favorable de impacto ambiental en la resolución de 21 de diciembre de 2000 (BOE $\mathrm{n}^{\circ}$ 14, de 16 de enero de 2001). La resolución favorable, emitida por la Dirección General de Calidad y Evaluación Ambiental del Ministerio de Medio Ambiente, fue precedida de un año de rigurosos trámites, en el que se valoró el documento técnico del proyecto, el estudio de impacto ambiental y el resultado de la información pública. Este proyecto contó, asimismo, con el acuerdo suscrito entre los gobiernos regionales de Castilla-La Mancha y Comunidad Valenciana en 1997, acuerdo que quedó plasmado en el artículo 32 del Plan Hidrológico del Júcar. 


\subsubsection{Breve descripción de la conducción Júcar-Vinalopó desde Cortes de Pallás}

En 1998, mediante el Plan Hidrológico de la cuenca del Júcar, se aprobó el trasvase de $80 \mathrm{hm}^{3} /$ año desde el Júcar al Vinalopó con el acuerdo de todos los afectados. Este trasvase contaba con Proyecto, Informe ambiental favorable e Informe favorable del BEI (Banco Europeo de Inversiones). Asimismo, contaba con subvención de fondos FEDER que aportaban 80,121 MM de $\square(34,70 \%)$, siendo financiada la obra mediante éstos, la aportación del Estado a través de Aguas del Júcar, S.A. que aportaría 75,685 MM de $\square(32,77 \%)$ y la de los usuarios, que aportarían 75,127 MM de $\square(32,53 \%)$ de los aproximadamente 230 MM de $\square$ presupuestados, comprometiéndose mediante el Convenio firmado en julio de 2001 entre la distintas comunidades de usuarios y Aguas del Júcar, S.A. En febrero de 2002 se constituyó la Junta Central de Usuarios. En enero de 2003 la Administración hidráulica ratificó el acuerdo de constitución de la Junta Central de Usuarios del Vinalopó, L'Alicantí y Consorcio de Aguas de la Marina Baja (JCU) para realizar la gestión de las aguas que lleguen por la conducción Júcar-Vinalopó. La obra fue declarada de interés general para el Estado, habiéndose adoptado en el proyecto medidas precautorias y correctoras ${ }^{4}$.

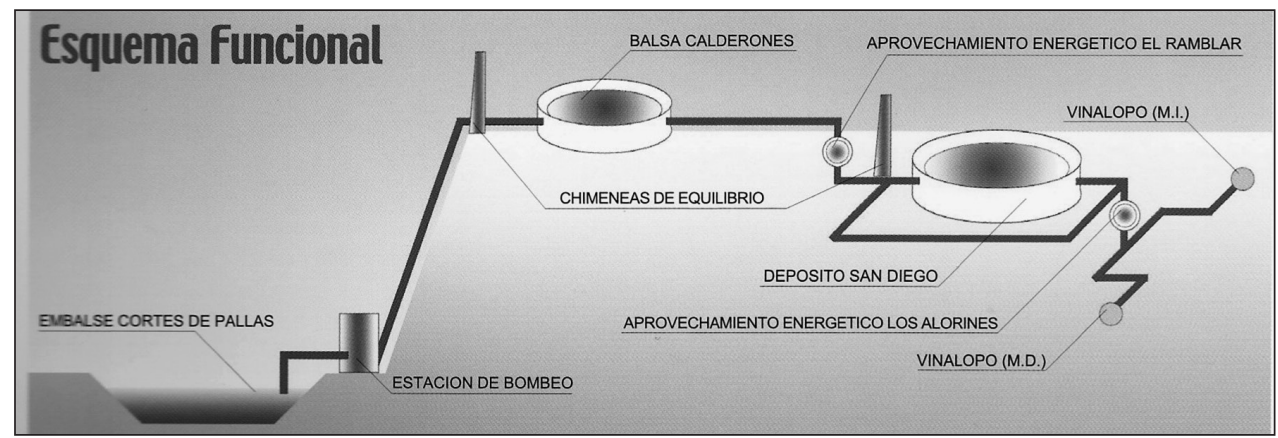

FiguRA 6. Esquema funcional de la conducción Júcar-Vinalopó.

Fuente: MIMAM: Aguas del Júcar, 2004.

4 Planificación de las obras en lugares de interés ornitológico. Realización de sistemas de drenaje para evitar afecciones en zonas de escorrentía. Plan de prevención de incendios forestales y plan de emergencia durante la ejecución de las obras. Delimitación del perímetro de las actuaciones para evitar desbroces innecesarios. Se evitará el vertido de aceites y residuos al suelo o a los cauces. Restauración del viario rural en su totalidad. Restauración de zonas de préstamos y de vertedero de nueva apertura. Transplante de las especies rupícolas a áreas cercanas con características similares. Acondicionamiento con tierra vegetal de las zonas a revegetar y protección de la erosión con muretes de piedra u otras medidas adecuadas. Evitar las voladuras con explosivos durante la época de de reproducción de la fauna. Recuperación de la capa de tierra vegetal para su uso en la restauración posterior. Regeneración del suelo y de la cubierta vegetal con especies autóctonas. Protección de la fauna. Señalización de tendidos eléctricos. Construcción de charcas. Se evitará la apertura de nuevos caminos, utilizando los ya existentes. La conducción proyectada tiene una longitud de $67 \mathrm{~km}$, siendo sus principales características las siguientes:

Conducción con tipologías de túnel y tubería enterrada.

Obra de toma y estación de bombeo.

Dos chimeneas de equilibrio.

- Dos depósitos de regulación:

1. Balsa inicial.

2. Depósito de San Diego de $20 \mathrm{hm}^{3}$ de capacidad.

- Dos minicentrales hidroeléctricas:

1. El Ramblar.

2. Los Alorines 
En noviembre de 2005, con todos los tramos licitados desde el año 2002, la obra estaba ejecutada en más del $52 \%$ de la inversión prevista.

El Gobierno, a través del Ministerio de Medio Ambiente, en verano de 2005, optó por cambiar la toma de la conducción, mediante una nueva alternativa consistente en realizar ésta en la cola del río Júcar, en el Azud de la Marquesa , Cullera (Valencia). Este cambio de trazado por parte de las autoridades hidráulicas obligó a revisar algunos documentos recientes de la misma Administración; así, en diciembre de 2004 la Administración española emite un Informe para la Comisión Europea sobre la conducción Júcar-Vinalopó, resaltando los siguientes aspectos:

- El 4-10-2002 El Gobierno informa a la Comisión de su propuesta de cofinanciación por el FEDER del proyecto «Conducción Júcar-Vinalopó».

- La Dirección General de Política Territorial de la Comisión solicita informe al BEI, que informó favorablemente.

- El 6-8-2003 la Comisión contesta al Gobierno indicándole que el proyecto podía ser considerado técnica, económica y ambientalmente viable. La respuesta de las autoridades españolas a los requisitos impuestos se realizó el 17-10-2003 y el 1011-2003.

- El 22-12-2003 la Comisión comunica al Gobierno su participación en el proyecto con $80.121 .368 \square(51,61 \%)$ sobre el coste subvencionable.

- Con este informe de diciembre de 2004 el Gobierno respondía a la Comisión sobre los requisitos exigidos por ésta en su escrito $\mathrm{n}^{\circ} 11549$ de 6-8-2003, sobre el programa de reducción del uso de aguas subterráneas en el área del Vinalopó-Alacantí-Marina Baja, también acerca del plan de actuación para conseguir una adecuada cobertura de los costes y sobre las conclusiones del estudio en marcha acerca de la Albufera de Valencia y la sostenibilidad de su ecosistema. ${ }^{5}$.

\subsubsection{Financiación del proyecto desde Cortes}

La inversión total del proyecto se estimó en $240.404 .841 \square$ (40.000 millones de pesetas), asumiéndose una desviación al alza del 20\% del presupuesto inicial (tabla 8).

5 Las características esenciales de la «Conducción Júcar-Vinalopó» (toma en Cortes de Pallas) se resumen a continuación:

- Longitud de la conducción: $69 \mathrm{~km}$, ejecutados mediante sifones enterrados de diámetro 1,95 m y túneles de 2,8 m. Estas soluciones limitan al máximo los impactos ambientales.

- Tramos de obra proyectados: 7.

- Toma: embalse de Cortes de Pallás (tramo I). Dimensionada para $10 \mathrm{~m}^{3} / \mathrm{s}$ para aprovechar la discriminación horaria en las tarifas eléctricas y provista de grupo de bombeo de reserva para emergencias y mantenimiento de la instalación. La toma necesita de una Línea Eléctrica de Media Tensión (LEMT) que tomará de una gran subestación eléctrica existente.

- Fin: proximidades de Villena (tramo VII).

- Embalses proyectados: uno, denominado embalse de San Diego, con una capacidad de $20 \mathrm{hm}^{3}$ y situado en cola, en el tramo 7.

- Capacidad de diseño de la conducción: 5,65 m³ $/ \mathrm{s}$, con un límite anual de $80 \mathrm{hm}^{3} / \mathrm{año}$.

- Altura de elevación: desde la cota 320 hasta la 820 , en $1 \mathrm{~km}$ de impulsión para discurrir por gravedad hasta la cota 540/575, para desde aquí alimentar la margen derecha y la margen izquierda cerca de Villena.

- Altura de elevación neta: 220/255 metros columna de agua (m.c.a.), empleándose el resto de energía consumida en el bombeo en superar las pérdidas de carga (unos 30 m.c.a.) como en las dos recuperaciones de energía mediante 2 minicentrales hidroeléctricas (Ramblar y Alorines).

- Grado de ejecución de las obras: tramo I (concluido), tramos II y III (más del 15\%), tramo IV (11\%), tramo V $(91 \%)$, tramo VI (prácticamente acabado) y tramo VII $(45 \%)$.

- Grado de ejecución del presupuesto: más del 52\% en noviembre de 2005. 
Tabla 8

FINANCIACIÓN DEL TRASVASE JÚCAR-VINALOPÓ

\begin{tabular}{|l|c|c|}
\hline Aguas del Júcar SA & $75.126 .513 \square$ & 12.500 mill. Ptas \\
\hline Fondos Estructurales UE & $90.151 .815 \square$ & 15.000 mill. Ptas. \\
\hline Aportación de los usuarios & $75.126 .513 \square$ & 12.500 mill. Ptas. \\
\hline Total financiación & $\mathbf{2 4 0 . 4 0 4 . 8 4 1} \square$ & $\mathbf{4 0 . 0 0 0 ~ m i l l . ~ P t a s ~}$ \\
\hline
\end{tabular}

Fuente: JCU, 2002.

La financiación del trasvase requirió la firma de un convenio entre los usuarios de la conducción Júcar-Vinalopó y la empresa pública Aguas del Júcar SA, en el que las Comunidades Generales de Usuarios del Alto y Medio Vinalopó-Campo de Alicante, respectivamente, más el Consorcio de Aguas de la Marina Baja asumieron la repercusión íntegra de los costes de explotación y una parte importante de la amortización de la obra a realizar (75,1 MM $\square$ ).

Según el Convenio firmado entre Aguas del Júcar SA y la Junta Central de Usuarios, estos últimos respondían con una aportación de 75.126.513 $\square$, quedando a cargo de Aguas del Júcar las desviaciones al alza del proyecto de inversión y, en su caso, a cargo del Estado a través de los Fondos FEDER de la Unión Europea ,merece ser recordado que el Vinalopó fue declarado «zona desfavorecida por limitaciones específicas», precisamente por los problemas de sobreexplotación de acuíferos.

La fórmula financiera elegida por los usuarios consistió en repercutir todos los costes, tanto los de amortización como los de explotación, sobre las tarifas del agua. El total de la aportación (75.126.513 $\square$ ) a cargo de los regantes y usuarios se repartía del siguiente modo: Marina Baja, 15.025.303 $\square$ (20\%); Alto Vinalopó, 13.456.661 $\square$ (18\%); y Medio Vinalopó-Alacantí, 46.644.549 $\square(62 \%)$.

El precio del agua, incorporando el mantenimiento anual del sistema de la conducción más la carga financiera por cuenta de los usuarios de los $75.126 .513 \square$, se estimó en las cifras recogidas en cada caso en la tabla 9.

Tabla 9

PRECIO DEL AGUA

\begin{tabular}{|l|c|c|}
\hline & $\square / \mathbf{m}^{\mathbf{3}}$ & Ptas/ $\mathbf{m}^{\mathbf{3}}$ \\
\hline Riego con tarifa de preferencia & 0,081 & 13,5 \\
\hline Riego con tarifa normal & 0,126 & 21,0 \\
\hline Abastecimiento con sustitución & 0,240 & 40,0 \\
\hline Abastecimiento sin sustitución & 0,270 & 45,0 \\
\hline
\end{tabular}

Fuente: JCU, 2002.

\subsubsection{El reparto de los caudales $\left(80 \mathrm{hm}^{3}\right)$, proyecto desde Cortes de Pallás, 2001}

Como puede verse en la tabla 10, los abastecimientos de agua potable de la Marina Baja recibirían, en principio, $11,5 \mathrm{hm}^{3} /$ año, lo que determina que el volumen de agua del Júcar que se debe dedicar a sustitución de extracciones estará comprendido entre 65 y $70 \mathrm{hm}^{3} /$ 
año. La sobreexplotación en el Vinalopó se estima entre 62 y 96 hm³/año, por lo que estos caudales de sustitución permitirán alcanzar una situación de equilibrio, lo que repercutirá en la estabilización de la piezometría.

Tabla 10

REPARTO DE CAUDALES

\begin{tabular}{|c|c|c|c|c|}
\hline & $\begin{array}{c}\text { Alto } \\
\text { Vinalopó }\end{array}$ & $\begin{array}{c}\text { Medio } \\
\text { Vinalopó }\end{array}$ & $\begin{array}{c}\text { Marina } \\
\text { Baja }\end{array}$ & TOTAL \\
\hline Riego con tarifa de preferencia & 6,3 & 6,3 & - & 12,6 \\
\hline Riego con tarifa normal & 6,3 & 26,1 & - & 32,4 \\
\hline Total Riego & 12,6 & 32,4 & - & 45,0 \\
\hline Abastecimiento con sustitución & 3,5 & 16,5 & - & 20,0 \\
\hline Abastecimiento sin sustitución & 0,5 & 3,0 & 11,5 & 15,0 \\
\hline Total Abastecimiento & 4,0 & 19,5 & 11,5 & 35,0 \\
\hline TOTAL & 16,6 & 5,9 & 11,5 & 80,0 \\
\hline
\end{tabular}

Fuente: JCU, 2002.

Dado que no se garantizaba que el caudal pudiera llegar en su totalidad todos los años, como referente se consideraron $32,40 \mathrm{hm}^{3}$ para regadío y $15 \mathrm{hm}^{3}$ para abastecimiento. Como alternativa, en los años de potenciales sequías, estarían los pozos que deberían ir recargándose de forma natural.

\subsection{Cambio de la toma de la conducción Júcar-Vinalopó al azud de la Marquesa (Culleral Valencia), noviembre de 2005}

El cambio de Gobierno tras las Elecciones Generales de marzo de 2004, trajo consigo un importante viraje en la política hidráulica a escala nacional, la primera victima de esta política fue la cancelación del trasvase del Ebro en junio de 2004, un año después le tocaría a la Conducción Júcar-Vinalopó sufrir sus consecuencias (Melgarejo, J.; 2008).

En julio de 2005, se entrega a la Comisión Técnica del trasvase Júcar-Vinalopó (CT) el documento titulado Propuesta de toma y trazado alternativo al actual proyecto de conducción entre los ríos Xúquer y Vinalopó, elaborado por la Subdirección General de Planificación Hidrológica de la Dirección General del Agua del MIMAM (DGA, 2005). El argumento esgrimido en este documento para el cambio de toma es una supuesta falta de disponibilidad de recursos hídricos en Cortes, frente a la existencia de dichos recursos en Cullera ${ }^{6}$.

Así, se planteó un nuevo cambio de trazado respecto a la «Solución Sur» (solución que había sido descartada en abril de 2005 por la Confederación Hidrográfica del Júcar), manteniendo la toma en el azud de La Marquesa (Cullera) pero trasladando el punto de entrega a las inmediaciones de Fuente de la Higuera, conectándose la nueva conducción con la que ya estaba en ejecución.

6 En el Informe de F. Cabezas, septiembre de 2005, se desmiente que el traslado de la toma al azud de la Marquesa asegure mayor disponibilidad de recursos para los usuarios del Vinalopó, en él se asegura que su ejecución trasvasando los $80 \mathrm{hm}^{3}$ apenas afectaría al déficit medio del regadío en un 1-2\% pasando del 14-15\% al $16 \%$ siendo inapreciable para el abastecimiento, pues existiendo un problema de falta de garantía en los riegos de la Ribera, este problema es independiente de la existencia o no de trasvase. 
Además del cambio de toma, en esta propuesta se modifica sustancialmente la solución de toma en La Marquesa estudiada con los modelos por la CT, reduciendo sensiblemente la capacidad de transporte de la conducción a menos de la mitad de la anteriormente considerada (figura 7).

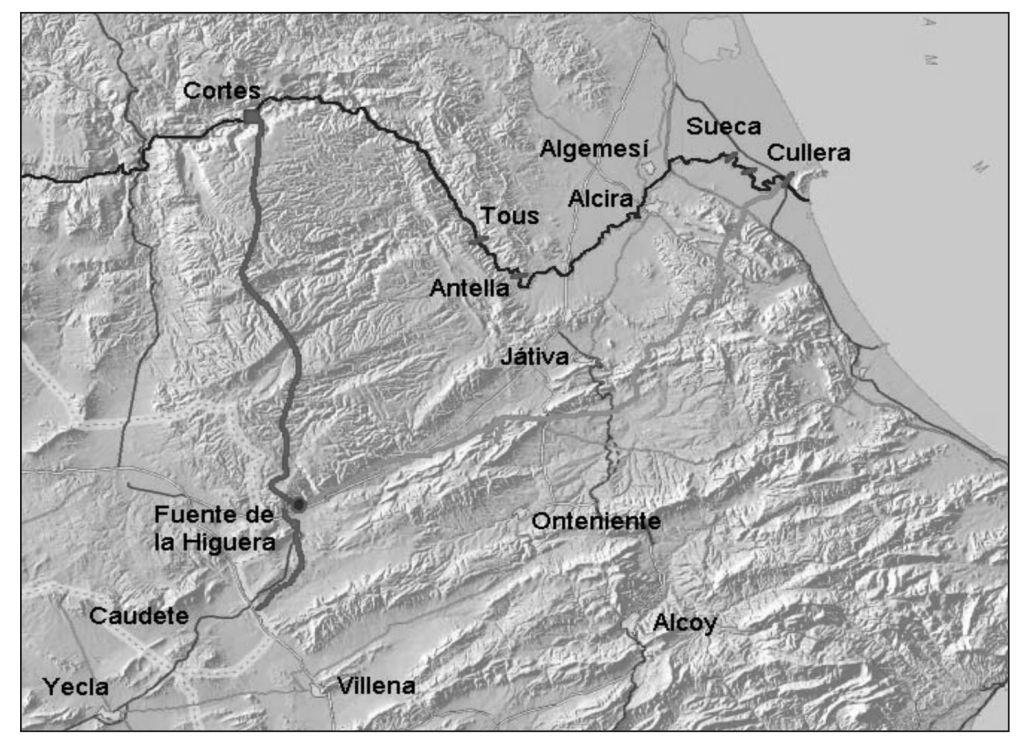

FIgURA 7. Trazados alternativos planteados.

Esta última alternativa propuesta por la DGA en julio de 2005 no había sido contemplada por Aguas del Júcar, S.A. en un documento de abril de 2005, siendo, por lo tanto, un planteamiento completamente nuevo y no conocido ni valorado con anterioridad por la CT, ni por la propia Sociedad Estatal, ni, cabe pensar, por la propia Confederación Hidrográfica, dado que en ninguno de sus documentos anteriores se alude a esta conducción (Cabezas, diciembre 2005).

También en julio de 2005, se presenta otro texto titulado Documento síntesis de las alternativas presentadas a la sesión del 28 de julio de 2005, con título en portada de la CT y firmado por Estevan y Lapuente (CTJV, 2005). El documento compara las alternativas enunciadas y concluye proponiendo el cambio de toma al azud de La Marquesa y la conducción de capacidad reducida sugerida en el documento de la DGA.

Finalmente, el 14 de noviembre de 2005 Aguas del Júcar S.A. redactó otro documento titulado Memoria-Resumen del Anteproyecto técnico de conexión del curso bajo del río Júcar con el tramo V. Conducción Júcar-Vinalopó (AJSA, 2005a). Según Cabezas (2005), este documento pretende constituir la Memoria-Resumen exigida por la legislación de evaluación de impacto ambiental a los efectos de la tramitación ambiental de un proyecto, pero sorprendentemente alude en su título a un Anteproyecto técnico que no existe, no pudiendo, en consecuencia, ser valorado ni técnica ni económica ni medioambientalmente. De acuerdo con este autor, cabe concluir que el desorden administrativo de todo este proceso es manifiesto y podría haber dado lugar a su nulidad. 
Las características de la citada Memoria-Resumen para la conexión entre el azud de la Marquesa y la conducción Júcar-Vinalopó en ejecución, se indican a continuación (AJSA, noviembre 2005).

\subsubsection{Descripción de la obra desde el azud de la Marquesa en Cullera-Tramo V. 2005}

El estudio de esta alternativa (CT, 2005) parte del documento de análisis de alternativas presentado a la sesión de la CT del trasvase Júcar-Vinalopó del 28 de julio de 2005; planteándose como solución factible para mejorar la garantía del recurso trasvasable en el actual punto de toma de la conducción: el Azud de la Marquesa, en Cullera, tramo final del cauce antes de su desembocadura en el estuario y última zona donde no hay otros usos, más que los puramente ambientales.

Se realizaron diversas modelizaciones del régimen hídrico del río en el azud de la Marquesa con el objeto de confirmar la garantía de recursos trasvasables, utilizando los mismos criterios y datos de partida utilizados en la simulación del régimen del río en el en el embalse de Cortes de Pallás. Se confirmó la existencia de suficientes recursos hídricos para cumplir con el Plan Hidrológico de la cuenca del Júcar.

La alternativa estudiada en la CT contemplaba una toma con una capacidad de $5,6 \mathrm{~m}^{3} / \mathrm{s}$, para la cual las simulaciones ofrecían una media de volumen trasvasable de 39,4 hmªño. Sin embargo, aún siendo este el mayor caudal disponible en cualquier punto del Júcar en Valencia, todavía resulta insuficiente para atender las necesidades del Vinalopó, por lo que se han estudiado medidas que pudieran reforzar la captación. Para ello se ha examinado la posibilidad de derivar hacia el Vinalopó una parte del caudal ecológico que debe llegar hasta el azud de la Marquesa, asegurando previamente la satisfacción de las necesidades ambientales del estuario. Estas necesidades pueden ser cubiertas mediante la combinación de dos recursos:

- Los caudales que no sean derivados al Vinalopó, bien sea porque excedan de la capacidad de la toma, o porque superen el volumen de trasvase autorizado.

- Los vertidos al mar de las golas del Mareny de Barraquetes y del Mareny de San Lorenzo, que desaguan actualmente al mar un considerable volumen de agua sin utilidad ambiental ni económica alguna. A salvo de aforos precisos que no están disponibles, se ha estimado en al menos $90 \mathrm{hm}^{3}$ anuales el volumen medio de vertido conjunto de estas golas ${ }^{7}$

Ello permite formular diversas estrategias de toma en el Azud de la Marquesa. A) La más inmediata era la de completar con aportaciones complementarias de las golas el volumen medio de 39,4 $\mathrm{hm}^{3} /$ año que las simulaciones indican que se podrían captar en el río con una toma de $5,6 \mathrm{~m}^{3} / \mathrm{s}$, lo cual permitiría alcanzar sin especiales dificultades $\operatorname{los} 70 \mathrm{hm}^{3}$ de media anual, con un máximo de $80 \mathrm{hm}^{3} / a$ ño. Los recursos de las golas no se trasvasarían al Vinalopó, sino que serían entregados al pie del azud de la Marquesa en sustitución de un flujo equivalente de caudal ambiental (aproximadamente $1 \mathrm{~m}^{3} / \mathrm{s}$ ), que es el que se derivaría al Vinalopó desde la lámina superior del Azud. De este modo, el caudal mínimo recibido

7 La calidad del agua de las golas es actualmente muy deficiente. No obstante, la calidad de estas aguas mejorará drásticamente una vez se cumplan las obligaciones de depuración pendientes en esa zona mediante la ampliación de la EDAR de Sueca. Los caudales de ambas golas pueden ser fácilmente derivados hasta el pie del Azud de la Marquesa, sin apenas coste de bombeo, y posiblemente utilizando secciones de la densa red de acequias existente, con los oportunos acondicionamientos. Operaciones similares de rebombeo se realizan normalmente en los arrozales. 
por el estuario no sufriría alteración alguna, pues la detracción de caudal hacia el Vinalopó sería compensada, en la base del Azud, con un flujo equivalente procedente de las golas. Obsérvese que esta solución también se podría adoptar tomando el agua en Cortes de Pallas. B) Otro posible planteamiento era basar la transferencia al Vinalopó en una toma continua de una fracción del caudal ambiental que llega hasta el azud de la Marquesa, suficiente para completar la transferencia, satisfaciendo las necesidades ambientales del estuario con una combinación de caudales variables procedentes de tres fuentes:

1. Los caudales ambientales no transferidos

2. Los recursos propios del río que superen el caudal ambiental, esto es, la media de $39,4 \mathrm{hm}^{3} /$ año que ya no se transfieren al realizarse la toma con cargo al caudal ambiental, más las avenidas.

3. Los recursos disponibles de las golas.

Lo expuesto anteriormente demuestra la incoherencia de esta propuesta, ya que si el agua en cola es adecuada para el regadío, el hecho de que se detraigan $80 \mathrm{hm}^{3} /$ año en Cortes, no empeorará su calidad, por lo que se pone de manifiesto la solución inadecuada de dejar descender el agua por el río para volver a elevarla a base de bombeos y mayores consumos energéticos a través de una complicada obra, más cara de ejecución y de mantenimiento, con problemas medioambientales y que ha retrasado los plazos de entrega sobre los inicialmente previstos en la solución de Cortes que, además, permitía el uso en abastecimientos y abarata su coste para los agricultores.

\subsubsection{Nuevo proyecto de conexión del curso bajo del río Júcar con el tramo V de la con-} ducción Júcar-Vinalopó, marzo de 2006

La nueva alternativa que superó la evaluación de impacto ambiental en mayo de 2006 tiene una longitud total de 77,670 Km., se inicia 50 m aguas arriba del azud de la Marquesa (Cullera), donde se prevé un caudal en continuo de 2,6 m³/s durante las 24 horas del día, y desde el cual las aguas entran en la cántara de la estación de bombeo del azud de la Marquesa, de 26,8 m de altura de elevación manométrica y $1.149 \mathrm{Kw}$. de potencia total, que funcionaría durante $24 \mathrm{~h}$ /día durante 264 días/año, lo que se traduce en un caudal de diseño de la estación de bombeo de $3,5 \mathrm{~m}^{3} / \mathrm{s}$. Este caudal es conducido mediante una conducción en $6.873 \mathrm{~m}$ de longitud, denominada Impulsión Marquesa-Panser.

En síntesis el trazado que une Cullera con el Tramo V de la Conducción Júcar-Vinalopó consta de 5 tramos:

El tramo A comprende la toma en el río Júcar, la estación de bombeo del azud de la Marquesa, la impulsión Marquesa-Panser, la balsa de regulación y estación de bombeo del Panser y la impulsión Corbera, así como el telemando de toda la conducción.

El tramo B comprende el túnel Sierra Corbera, el sifón de Aigües Vives-Simat y el túnel Barxeta.

El tramo C comprende el sifón de Barxeta-Xàtiva.

El tramo D comprende la balsa de regulación y estación de bombeo de Llanera de Ranes y un primer tramo de la impulsión Costera de $17.971 \mathrm{~m}$ de longitud.

Por último, el tramo $\mathbf{E}$ comprende el tramo restante de la impulsión Costera, de $7.015 \mathrm{~m}$ de longitud, la balsa de regulación y estación de bombeo de Venta del Potro y la impulsión Venta del Potro, incluyendo la conexión con el tramo V de la conducción Júcar-Vinalopó. 
La calidad del agua en el Azud de la Marquesa sólo permite el uso para regadío quedando por concretar la distribución geográfica de los caudales a trasvasar. En fechas recientes el secretario de Estado J.Puxeu reconocía la necesidad de crear una planta potabilizadora que hiciera posible la totalidad de los usos, en la actualidad, noviembre de 2010, sobre esta cuestión no existe ningún compromiso firme reflejado en los presupuestos del Ministerio de Medio Ambiente Rural y Marino. En las figuras 3 y 4 se observa el perfil longitudinal de la conducción.

En la figura 8 se muestra el esquema hidráulico general de la conducción con los distintos tramos y el perfil longitudinal esquemático de la conducción completa.

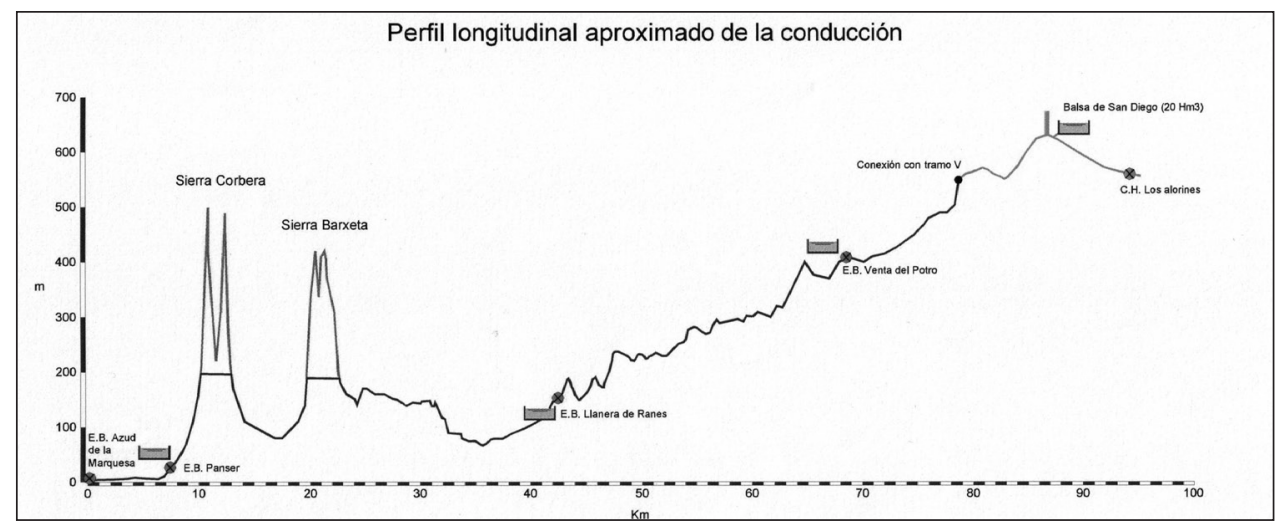

\subsubsection{Presupuesto y otras consideraciones}

La estructura presupuestaria adoptada conduce a la valoración económica que se sintetiza en la tabla 11. Al Presupuesto de Ejecución Material, se le ha afectado un 13\% de Gastos Generales y el 6\% de Beneficio Industrial y, a la suma de todo ello, el 16\% correspondiente al IVA. Como se puede observar, el presupuesto base de licitación ascendió en 2006 a 213.608.275,13 $\square$.

Tabla 11

PRESUPUESTO DE LAS OBRAS POR TRAMOS

\begin{tabular}{|c|c|c|}
\hline \multicolumn{3}{|c|}{ PRESUPUESTO DE LAS OBRAS } \\
\hline CAPÍTULO & $\begin{array}{c}\text { IMPORTE } \\
\text { (口) }\end{array}$ & $(\%)$ \\
\hline 1. Obra de toma & $1.658 .564,64$ & 1,1 \\
\hline 2. Estación de bombeo azud de la Marquesa & $3.826 .723,77$ & 2,5 \\
\hline 3. Impulsión Marquesa-Panser & $7.039 .622,06$ & 4,5 \\
\hline 4. Balsa Panser & $3.093 .635,88$ & 2,0 \\
\hline 5. Estación de bombeo Panser & $9.219 .820,62$ & 6,0 \\
\hline 6. Impulsión Corbera & $3.739 .277,08$ & 2,4 \\
\hline
\end{tabular}


7. Túnel sierra Corbera

$6.969 .619,54 \quad 4,5$

8. Sifón aigües Vives-Simat

$7.515 .257,52$

9. Túnel Barxeta

$7.405 .228,68$

4,8

10. Sifón Barxeta-Xàtiva

23.667.968,71

15,3

11. Balsa LLanera de Ranes

1.377.224,73 $\quad 0,9$

12. Estación de bombeo LLanera de Ranes

$8.557 .075,39$

5,5

13. Impulsión Costera 1

23.317.918,04 $\quad 15,1$

14. Impulsión Costera 2

$10.931 .356,32$

15. Balsa venta del Potro

$987.271,20 \quad 0,6$

16. Estación de bombeo venta del Potro

11.294.016,01

7,3

17. Impulsión venta del Potro

$15.112 .197,05$

9,8

18. Telemando

$364.453,57$

0,2

19. Correcciones medioambientales

$7.013 .492,00$

4,5

20. Seguridad y salud

$1.653 .029,10$

1,1

\begin{tabular}{lrrr}
\hline Presupuesto de ejecución material & $\mathbf{1 5 4 . 7 4 3 . 7 5 1 , 9 1}$ & $\mathbf{1 0 0 , 0}$ \\
\hline Gastos generales (13\%) & $20.116 .687,75$ & \\
\hline Beneficio industrial (6\%) & $9.284 .625,11$ & \\
\cline { 2 - 3 } & Suma (口) & $\mathbf{1 8 4 . 1 4 5 . 0 6 4 , 7 7}$ & \\
I.V.A. (16\%) & $29.463 .210,36$ & \\
\hline Presupuesto base de licitación ( $\square)$ & $\mathbf{2 1 3 . 6 0 8 . 2 7 5 , 1 3}$ & $\mathbf{1 0 0 , 0}$
\end{tabular}

Fuente: AJSA (marzo-2006).

En la tabla 12 se detalla el presupuesto de ejecución material y el presupuesto base de licitación de cada uno de los tramos. El Presupuesto de Ejecución Material de cada tramo se forma por la suma de los presupuestos de cada uno de los capítulos de obra recayentes al mismo, más la parte proporcional, en función de dicho importe parcial, de los capítulos de Correcciones Ambientales y Seguridad y Salud (AJSA, marzo/2006).

Tabla 12

PRESUPUESTO BASE DE LICITACIÓN

\begin{tabular}{|l|r|r|r|}
\hline \multicolumn{1}{|c|}{ Tramo } & P.E.M. ( $\square)$ & $\begin{array}{c}\text { Presupuesto base de } \\
\text { licitación }(\square)\end{array}$ & \multicolumn{2}{c|}{$\begin{array}{c}\text { Porcentaje } \\
(\mathbf{\%})\end{array}$} \\
\hline A & $30.659 .184,52$ & $42.321 .938,31$ & 27,35 \\
\hline B & $23.188 .809,60$ & $32.009 .832,78$ & 22,69 \\
\hline C & $25.072 .150,25$ & $34.609 .596,21$ & 31,42 \\
\hline D & $35.225 .017,40$ & $48.624 .614,01$ & 36,22 \\
\hline E & $40.598 .590,14$ & $56.042 .293,82$ & $\mathbf{1 3 8 , 0 5}$ \\
\hline TOTAL & $\mathbf{1 5 4 . 7 4 3 . 7 5 1 , 9 1}$ & $\mathbf{2 1 3 . 6 0 8 . 2 7 5 , 1 3}$ & \\
\hline
\end{tabular}

Fuente: AJSA (marzo-2006) 
En esta Memoria se detalla, además, que adoptando el presupuesto aproximado de expropiaciones e indemnizaciones, considerando el Plan de Vigilancia y Control de las Obras, y añadiendo el 1\% del Presupuesto de Ejecución Material en concepto de Patrimonio Histórico Español, resulta un presupuesto para conocimiento de la Administración de 231.580.343,30 $\square$.

Este Presupuesto no contempla el coste de las obras ejecutadas y aprovechadas para la nueva alternativa de trasvase ni tampoco las obras ejecutadas y que no serán aprovechables definitivamente. Tampoco considera la tarifa que tendrán que pagar los agricultores sabiendo que el agua no será aprovechable para los abastecimientos urbanos e industriales; ni por supuesto, qué cantidad del coste real será subvencionada por la Administración del Estado. Según las estimaciones de Melgarejo, P. y Melgarejo, J. (2006b) el presupuesto de esta nueva alternativa ascendería a 351.000.000 $\square$, ya que al presupuesto de 231.580.343 aprobado en 2006 hay que sumar las partes ejecutadas o en ejecución aprovechables de la Conducción desde Cortes de Pallas: parte del tramo V y los tramos VI y VII. A ello habría que sumar los presupuestos ya ejecutados que no se van a utilizar (costes hundidos), es decir, los tramos I, II, III, IV y parte del V de la Conducción desde Cortes de Pallás, que se estimó en 73.500.000 $\square$. Por tanto, el coste estimado de la nueva alternativa ascendería a $424.500 .000 \square^{8}$.

Según la Delegación del Gobierno en la Comunidad Valenciana en mayo de 2010, la Conducción (trasvase) Júcar-Vinalopó, representa una inversión total de algo más de 320 millones de euros y cuenta con una subvención de fondos FEDER de unos 120 millones de euros; la cantidad no aportada por la Unión Europea corre a cargo del Gobierno de España (aproximadamente 148 millones de euros) y financiación externa (bancaria) ${ }^{9}$.

Por otro lado, en el Anejo 19 de la Memoria (AJSA, marzo-2006): Costes de explotación, se analizan los costes repercutibles al usuario (tabla 13). Para ello AJSA prevé que la inversión repercutible a los usuarios asciende a 75 millones de euros, con un periodo de amortización de 50 años y una tasa de descuento a aplicar en el análisis financiero del $4 \%$, con lo que se obtendría una amortización anual de 3,49 millones de euros. Con estas consideraciones el precio final a satisfacer por los usuarios sería de 0,196 $\square$.

No se explica por qué se considera un trasvase de $70 \mathrm{hm}^{3} / \mathrm{año}$, cuando la previsión del Plan Hidrológico de la cuenca del Júcar es de 80 hm³/año. Los usuarios (JCU) nunca aceptaron estas cuentas, ya que una vez que se había consumado el cambio de la toma, con su oposición, éstos se sintieron liberados de sus compromisos e incluso renunciaron al crédito sindicado que habían contraído, pagando los costes en que habían incurrido.

8

\begin{tabular}{|l|r|}
\hline \multicolumn{1}{|c|}{ Concepto } & Presupuesto ( $\square$ ) \\
\hline A) Presupuesto contemplado en la nueva alternativa & $213.580 .343,3$ \\
\hline $\begin{array}{l}\text { B) Presupuesto de esta alternativa incluyendo el aprovechamiento de parte del tramo V y } \\
\text { los tramos VI y VII de la antigua conducción desde Cortes }\end{array}$ & $351.000 .000,0$ \\
\hline $\begin{array}{l}\text { C) Presupuesto ejecutado de los tramos I, II, III, IV y parte del V de la antigua conducción } \\
\text { desde Cortes }\end{array}$ & $73.500 .000,0$ \\
\hline & Presupuesto B) +C)
\end{tabular}

Fuente: Melgarejo, P. y Melgarejo, J.: 2006b.

9 Delegación del Gobierno en la Comunidad Valenciana (2010): «Prácticamente finalizado el trasvase Júcar-Vinalopó». Boletín Semanal, nº 116, mayo de 2010. 
Tabla 13

COSTES REPERCUTIBLES A LOS USUARIOS DEL TRASVASE

\begin{tabular}{|c|c|}
\hline Inversión repercutible $(\square)$ & $75.000 .000,00$ \\
\hline Amortización de la inversión ( $\square / a \tilde{n} o)$ & $3.490 .000,00$ \\
\hline 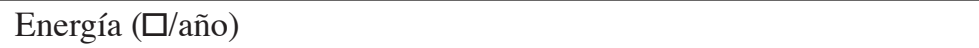 & $7.351 .449,40$ \\
\hline Ingresos por turbinación ( $\square /$ año) & $-711.030,00$ \\
\hline Conservación y mantenimiento ( $\square /$ año) & $3.559 .867,32$ \\
\hline Total costes de explotación ( $\square /$ año) & $10.200 .286,72$ \\
\hline Total costes repercutibles ( $\square /$ año) & $13.690 .286,72$ \\
\hline \multirow[t]{2}{*}{ Volumen trasvasable ( $\left.\mathrm{hm}^{3} / \mathrm{año}\right)$} & 70,00 \\
\hline & 0,196 \\
\hline
\end{tabular}

Fuente: AJSA (marzo-2006).

En marzo de 2010, acuaJúcar (Aguas de la cuenca del Júcar) presento la licitación para contratar los servicios de operación y mantenimiento de las obras de transferencia y regulación que conforman la infraestructura denominada «Conducción Júcar-Vinalopó», el presupuesto de la propuesta ascendió a 1,9 M $\square$ más IVA. En la licitación aparecen el conjunto de las obras y su grado de ejecución en enero de 2010 (tabla 14). La empresa adjudicataria de los servicios de operación y mantenimiento es Acuagest Levante S.A. En mayo de 2010 se realizó una simulación sobre los potenciales costes de explotación de la Conducción, tomando como referencia un volumen medio trasvasable de $70 \mathrm{hm}^{3} /$ año, sin tener en cuenta la amortización de las obras, es decir, se contemplan como costes, los fijos de explotación y los costes variables, principalmente energía. El coste total de la simulación asciende a $0,275 \square / \mathrm{m}^{3}$ (tabla 15), que podríamos considerar como los costes teóricos del agua para regadío; mientras que el agua para abastecimiento ${ }^{10}$ se situaría en una horquilla entre $0,4083 \square / \mathrm{m}^{3}$ y $0,4612 \square / \mathrm{m}^{3}$. Cifras notablemente superiores a la que se ofreció en 2006 por la empresa pública Aguas del Júcar S.A., que si incluía amortización, de 0,19 $\square$ / $\mathrm{m}^{3}$ (ver tabla 13). Y, muy superiores a las que habían acordado los usuarios en $2002^{11}$ con la toma en Cortes de Pallás, que incluyendo la amortización de los 75,1 MM $\square$ a los que se habían comprometido y los costes de mantenimiento, variaba según fuera para regadío entre $0,12 \square / \mathrm{m}^{3}$ y $0,24 \square / \mathrm{m}^{3}$ si era para abastecimiento ${ }^{12}$.

10

\begin{tabular}{|c|c|c|c|}
\hline Costes de abastecimiento & \multicolumn{3}{|c|}{$\begin{array}{c}\square / \mathrm{m}^{3} \\
\mathrm{Va}=\mathbf{3 2 , 8 3} \mathrm{hm}^{3}\end{array}$} \\
\hline Coste de explotación TJV sin amortizaciones & \multicolumn{3}{|c|}{0,275} \\
\hline Coste potabilización sin y con estación depuradora & & & 0,1495 \\
\hline Coste de postrasvase abastecimiento & \multicolumn{3}{|c|}{0,0367} \\
\hline TOTAL & 0,4083 & \multicolumn{2}{|c|}{0,4612} \\
\hline
\end{tabular}

11 Junta Central de Usuarios (JCU) (2002): Operación de Préstamo Sindicado. Memorandum Informativo. CAM, Alicante.

12 Los costes de explotación del trasvase Júcar-Vinalopó, convenidos por la JCU con la Administración en 2002, ascendían a $1518 \mathrm{M}$ de pesetas para $80 \mathrm{hm}^{3} /$ año transferidos; lo que equivale a unos costes unitarios de $0,114 \square / \mathrm{m}^{3}$, a éstos abría que sumar los costes de amortización de capital que eran de $0,061 \square / \mathrm{m}^{3}$. Ambos costes ascendían a $0,175 \square / \mathrm{m}^{3}$ (JCU, 2002). 
El agua del Júcar debía haber llegado al Vinalopó en marzo de 2007. El cambio de toma y trazado adoptado en 2005 por el Ministerio de Medio Ambiente ha significado un importantísimo retraso, que ha provocado, según M. Senent (2008:69), un sobrecoste a los potenciales usuarios de $0,03 \square$ por cada metro cúbico que no ha sido trasvasado $\mathrm{y}$, en consecuencia, ha tenido que ser bombeado de los acuíferos del sistema Vinalopó.

Tabla 14

GRADO DE EJECUCIÓN DE LA OBRA EN ENERO DE 2010

CONDUCCION JUCAR-VINALOPO. Estado ejecución

\begin{tabular}{|c|c|c|c|c|}
\hline TRAMO & $\begin{array}{c}\text { EMPRESA ADJ } \\
\text { UTE,S } \\
\end{array}$ & $\begin{array}{l}\text { FECHA FIN } \\
\text { CONTRACTUAL }\end{array}$ & NOTAS PREVSION PUESTA EN MARCHA & $\begin{array}{l}\text { \% EJECUTADO } \\
\text { final enero } 2010\end{array}$ \\
\hline A (Mar ques a-Corber a) & DRAGADOS-CLEOP & 18-abr-10 & $\begin{array}{l}\text { Pendiente aprabación Modif 1: Linea eléctrica } \\
\text { Subterránea a Benicull }\end{array}$ & $83,4 \%$ \\
\hline B (Túneles y sifón Aigües Vives) & OHL-L.SERRANOS-OCIDE & $14 / 07 / 2010\left({ }^{*}\right)$ & $\begin{array}{l}\text { Finalzado Túnel Corbera. En ejecución túnel Barxeta } \\
\text { (por dos bocas). (*) Fecha contrachual 14julio } 2010 .\end{array}$ & $72,0 \%$ \\
\hline C (Sifón Barxeta- Llanera R) & VIAS-ROMYMAR & 28-mar-co & $\begin{array}{l}\text { Finalizado. Llenado desde rio Albaida. Probado y en } \\
\text { garantia }\end{array}$ & $100,0 \%$ \\
\hline D (Bombeo Llanera-Moixent) & FCC-PAVASAL & $30-5 \in p-09$ & $\begin{array}{l}\text { Finalizado. Llenado desde rí Albaida En pruebas y } \\
\text { remates }\end{array}$ & $95,0 \%$ \\
\hline E (Bombeo Moixent-Ramblar) & ACCIONA-C. LUAAN & 08-oct-09 & $\begin{array}{l}\text { Prácticamente finalizado. En pruebas y remates. } \\
\text { Pendientes linea } 132 \mathrm{kV} \text { lberdrola DSAU }\end{array}$ & $91,0 \%$ \\
\hline V (Sifón Ramblar - San Diego) & FERROVIAL-SEDESA & 01-feb-07 & Finalizado. Pendiente de puesta en carga. & $100,0 \%$ \\
\hline VI (Sifón S Diego - CH Alorines) & FCC-PAVASAL & 05-mar-07 & Finakizado. Pendiente de puesta en carga. & $100,0 \%$ \\
\hline VII (Bals a S Diego $20 \mathrm{Hm} 3$ ) & SACYR-CLEOP & 18-dic-08 & $\begin{array}{l}\text { Finalizado. En garantia. Pendiente ejecución Puesta en } \\
\text { Carga. }\end{array}$ & $100,0 \%$ \\
\hline Resto conceptos & Iberdrola, etc. & & En ejecución con la obra & $90,0 \%$ \\
\hline
\end{tabular}

Fuente: acuaJúcar, 2010.

Tabla 15

COSTES DE EXPLOTACIÓN DE LA CONDUCCIÓN JÚCAR-VINALOPÓ, MAYO 2010

\begin{tabular}{|l|c|c|}
\hline $\begin{array}{l}\text { Costes de explotación de la Conducción } \\
\text { Júcar-Vinalopó }\end{array}$ & $\begin{array}{c}\text { Costes } \\
\text { Máximo }\end{array}$ & $\begin{array}{c}\text { Costes: } \mathbf{~ m}^{\mathbf{3}} \\
\text { V=70 hm }\end{array}$ \\
\hline Costes fijos de explotación & $\mathbf{2 , 3 5 8} \mathrm{M} \square / \mathbf{a n ̃ o}$ & $\mathbf{0 , 0 3 4} \square / \mathbf{m}^{3}$ \\
\hline $\begin{array}{l}\text { Costes variables de explotación } \\
\text { ( Energía + Resto de costes variables }\end{array}$ & $\begin{array}{c}\mathbf{1 5 , 0} \mathrm{M} \square / \mathbf{a n ̃ o} \\
+\mathbf{1 , 9} \mathrm{M} \square / \mathbf{a n ̃ o}\end{array}$ & $\begin{array}{c}\mathbf{0 , 2 1 4} \square \mathbf{m}^{3}+\mathbf{0 , 0 2 7} \square \\
\mathbf{~ m}^{\mathbf{3}}\end{array}$ \\
\hline & Total & $\mathbf{0 , 2 7 5} \square / \mathbf{m}^{3}$ \\
\hline
\end{tabular}

\section{Conclusiones}

Desde hace varios años se viene produciendo una reducción en las superficies regadas del Vinalopó, fenómeno que está ligado a los importantes descensos producidos en los niveles piezométricos de las unidades hidrogeológicas de la zona, siendo estos descensos de hasta 80 metros en algunos sistemas de explotación. Si estos descensos persisten en el futuro pueden acentuar los problemas de insostenibilidad a medio y largo plazo, manifestada ésta 
por la pérdida de calidad del recurso y por la pérdida de garantía para los abastecimientos urbanos que toman agua de estas unidades hidrogeológicas.

Las demandas reales en el espacio Vinalopó-Alancantí, no satisfechas en su totalidad, ascienden a más de $200 \mathrm{hm} 3 /$ año, mientras que los derechos sobre las mismas elevarían esta cifra hasta los $226 \mathrm{hm}^{3} /$ año. La Confederación Hidrográfica del Júcar evaluó, en 2004, el déficit total en las UHG del Vinalopó en 147,48 hm³/año, lo que coincide con la estimación realizada por la Junta Central de Usuarios en 2005. La Confederación realizó un balance hídrico con las cifras de extracciones, cifrándose un déficit próximo a $95 \mathrm{hm}^{3} /$ año. El volumen de sustitución propuesto para restablecer el equilibrio hídrico es de 68,3 $\mathrm{hm}^{3}$, que junto con el volumen de $11,5 \mathrm{hm}^{3}$ previstos para el abastecimiento a la Marina Baja, resultaría un total de $80 \mathrm{hm}^{3} /$ año a trasvasar desde el Júcar al Vinalopó.

El volumen total «controlado» extraído de los pozos del Vinalopó ascendió a 100,5 $\mathrm{hm}^{3}$ en 2005. Esta cantidad se distribuyó del siguiente modo: el 18,5\% en L'Alacantí, el $38 \%$ en el Alto Vinalopó y el 43,5\% en el Medio Vinalopó. La evolución de los distintos acuíferos del Vinalopó indica una acusada caída de los niveles piezométricos. En algunos casos la profundidad de las extracciones supera los $500 \mathrm{~m}$, como es en el de la Sierra de Crevillente. El descenso medio anual es variable en los diferentes acuíferos, oscilando entre los 2,6 m/año en el de Jumilla-Villena y los 9,4 m/año en Carche-Salinas.

La solución a la sobreexplotación de los acuíferos del Vinalopó estaba bien definida mediante la conducción Júcar-Vinalopó desde Cortes de Pallás, como ha quedado demostrado en este trabajo. El trasvase desde Cortes habría permitido evitar las situaciones de precariedad e insostenibilidad actuales, reduciendo el riesgo de abandono por falta de disponibilidad de recursos a corto plazo.

La paralización de las obras de la Conducción Júcar-Vinalopó: solución Cortes y su sustitución por el nuevo proyecto desde Cullera dificulta considerablemente la recuperación de los acuíferos sobreexplotados. El nuevo trazado con toma en Cullera, previsto en el proyecto aprobado en marzo de 2006, imposibilita, en la actualidad, los aportes a la cuenca del Vinalopó de agua para abastecimientos, fundamentalmente por razones de calidad, lo que a su vez influye negativamente en los costes que soportaría el regadío.

Con la solución desde Cortes de Pallás, el coste para los agricultores se fijó entre 0,081 y $0,126 \square / \mathrm{m}^{3}$ (acordado mediante Convenio entre los usuarios en 2002). Mientras que con la solución desde el azud de la Marquesa (marzo, 2006), el precio propuesto por Aguas del Júcar fue de $0,19 \square / \mathrm{m}^{3}$, sin que existiera acuerdo con los usuarios. En mayo de 2010 la simulación realizada de posibles tarifas, que no contempla amortización alguna, asciende el coste a $0,27 \square / \mathrm{m}^{3}$ para regadío y para abastecimiento el precio estaría entre 0,40 y $0,46 \square / \mathrm{m}^{3}$.

Las obras de la Conducción Júcar-Vinalopó desde Cortes estaban ejecutadas a más de un $52 \%$ en noviembre de 2005 y su coste real ascendía a $240 \mathrm{MM}$ de $\square$, por lo que las incertidumbres presupuestarias eran mínimas. La eficiencia energética de la instalación de bombeo en Cortes era muy superior a la solución planteada desde el azud de la Marquesa, debido principalmente a la mayor altura de elevación en esta última. Los costes de explotación con la toma en Cullera duplican ampliamente a los de Cortes, sea cual sea el volumen potencialmente trasvasado.

El punto de toma no es decisivo para determinar las posibilidades de trasvase, ya que éstas dependen de las disponibilidades globales del Sistema y de los criterios y prioridades de asignación. En Cortes existen recursos suficientes para realizar el trasvase Júcar-Vinalopó, por lo que las posibles incertidumbres hidrológicas han sido conocidas y aceptadas desde el principio por sus beneficiarios, los usuarios del Vinalopó.

La solución Cortes tenía capacidad teórica para trasvasar hasta $160 \mathrm{hm}$ 3/año, si funcionaba de forma continua. Ello, sin pretender superar el volumen máximo permitido $\left(80 \mathrm{hm}^{3} / \mathrm{año}\right)$, 
lo que posibilitaba hacer una gestión plurianual de la infraestructura, bien para trasvasar más agua en los años con mayores recursos, sin que la media excediese del máximo indicado, o bien para adquirir recursos a través de mecanismos de mercado, lo que permitía un doble o triple uso (uso normal, excedentes y mercado del agua), reduciendo los costes de inversión por metro cúbico trasvasado.

Entendemos que no existen razones fundadas de orden hidrológico, económico, medioambiental, jurídicas, sociales, ni de eficiencia energética, que aconsejaran el cambio de toma, más bien al contrario creemos que este trabajo ha demostrado la idoneidad de la solución con toma en Cortes sobre la de Cullera.

La solución desde el azud de la Marquesa no ha sido reclamada ni deseada por nadie, ni por los usuarios del Júcar ni por los del Vinalopó, ni por la Administración Autonómica, lo que constituye una anomalía histórica, sobre todo cuando el coste de la obra y su mantenimiento, las repercusiones ambientales y el coste final del agua trasvasada son muy superiores a los que se obtienen con la solución de Cortes.

En diciembre de 2010 están previstas las pruebas técnicas de la Conducción JúcarVinalopó. Sin embargo, siguen pendientes algunas cuestiones esenciales para el correcto funcionamiento de la infraestructura: la calidad del agua y las tarifas a aplicar. Oficialmente nada se sabe de la prometida potabilizadora, valorada en $40 \mathrm{M} \square$, que debe garantizar que el agua es apta para el abastecimiento y regadío. En cuanto al precio que habrán de pagar los usuarios, éstos a través de la Junta Central de Usuarios ya han manifestado su negativa a asumir costes superiores a los $0,18 \square / \mathrm{m}^{3}$, cifra notablemente inferior a los $0,275 \square / \mathrm{m}^{3}$ que se han estimado de costes unitarios de funcionamiento, sin tener en cuenta gastos de amortización. Se corre el riesgo de tener una infraestructura terminada sin usuarios.

\section{Biliografía}

AcuaJúcar (2010): Pliego de prescripciones técnicas particulares para la contratación de los servicios de operación y mantenimiento de las infraestructuras de la Conducción Júcar-Vinalopó. Marzo 2010.

Aguas del Júcar, S.A. (2005 a): Memoria-Resumen del Anteproyecto técnico de conexión del curso bajo del río Júcar con el tramo V. Conducción Júcar-Vinalopó. 14 noviembre 2005.

Aguas del Júcar, S.A. (2005b): Análisis del cambio de toma del Júcar-Vinalopó de Cortes al azud de la Marquesa. Abril 2005.

Aguas del Júcar, S.A. ( 2006). Proyecto informativo de conexión del curso bajo del río Júcar con el tramo V. Nueva conducción Júcar-Vinalopó. Marzo 2006.

BRU RONDA, C. (1988): «El trasvase Júcar-Vinalopó». En Demanda y Economía del agua en España. CAM, Alicante. pp. 287-300.

CABEZAS, F. (2005): Trasvase Júcar-Vinalopó. Análisis de alternativas. JCU. Villena.

Comisión Técnica del trasvase Júcar-Vinalopó (2005): Documento síntesis de las alternativas presentadas a la sesión del 28 de julio de 2005, A. Estevan y E. Lapuente, Valencia, julio 2005.

Confederación Hidrográfica del Júcar (2004): Informe para la Comisión Europea sobre la conducción Júcar-Vinalopó. Comunidad Valenciana (España). Diciembre de 2004.

Delegación del Gobierno en la Comunidad Valenciana (2010): «Prácticamente finalizado el trasvase Júcar-Vinalopó». Boletín Semanal, nº 116, mayo de 2010.

DÍAZ MARÍN, P. (2005): «Antecedentes históricos del trasvase del Júcar: la utopía hidráulica de la burguesía alicantina en el siglo XIX». Congreso Nacional Gestión del Agua en Cuencas Deficitarias.

GIL OLCINA, A. (1992): «Desequilibrios hidrográficos en España y trasvases a la vertiente mediterránea. Utopías y realizaciones. Investigaciones Geográficas, no 10, pp. 7-23.

Junta Central de Usuarios (JCU) (2002): Operación de Préstamo Sindicado. Memorandum Informativo. CAM, Alicante.

MELGAREJO, J. (Ed.) (2004). Repercusiones socioeconómicas del plan hidrológico nacional en la provincia de Alicante. COEPA. Alicante. 
MELGAREJO, J. (2008): «Las guerras del agua en la España democrática», CUIDES, nº 1.

MELGAREJO, P. y MELGAREJO, J. (2006): Informe sobre la conducción Júcar-Vinalopó y la nueva alternativa planteada para la toma en la desembocadura. COEPA. Alicante. Enero 2006.

MELGAREJO, P y MELGAREJO, J. (2006): Sobreexplotación de acuíferos en la cuenca del Vinalopó y propuestas de solución. JCU, Alicante. Junio 2006.

MELGAREJO, J., MOLINA, A. y BLANES, M. A. (2006): Análisis jurídico-económico de la sentencia del Tribunal Supremo de 20 de octubre de 2004 por la que se anulan diversos artículos del Plan Hidrológico de la cuenca del Júcar. Revista Aranzadi de Derecho Ambiental, pp. 129-156.

MIMAM. (2004): Informe de recuperación de costes, cuenca del Júcar. Madrid.

MIMAM. (2005): Propuesta de toma y trazado alternativo al actual proyecto de conducción entre los ríos Xuquer y Vinalopó. Madrid, julio 2005.

MIMAM/ Aguas del Júcar S.A. (2004): Un proyecto solidario: Conducción Júcar-Vinalopó.

PRAT, D. y MELGAREJO, J. (2006): Desalación y reutilización de aguas. Situación en la provincia de Alicante. COEPA. Alicante.

RICO, A. (2002): «Escasez de recursos de agua y planteamientos de trasvases en la provincia de Alicante: La transferencia Júcar-Vinalopó». Ed. A. Gil Olcina y A. Morales Gil: Insuficiencia Hídricas y Plan Hidrológico Nacional. Alicante.

RICO, A. (2005): Alegaciones a la Memoria-Resumen. Diciembre de 2005.

SENENT ALONSO, M. (Dir.) (2008): Costes de explotación de las aguas subterráneas en el sistema Vinalopó-L'Alacantí. Instituto Universitario del Agua y del Medio Ambiente. Universidad de Murcia. 
